\title{
Space Charge Property of Polyethylene/Silica Nanocomposites at Different Elongations
}

\author{
Can Wang, Youyuan Wang, Peng Fan, and Ruijin Liao \\ State Key Laboratory of Power Transmission Equipment \& System Security and New Technology, Chongqing University, \\ Chongqing 400030, China \\ Correspondence should be addressed to Can Wang; 20094589@cqu.edu.cn
}

Received 22 December 2014; Revised 14 February 2015; Accepted 12 March 2015

Academic Editor: Mircea Chipara

Copyright (C) 2015 Can Wang et al. This is an open access article distributed under the Creative Commons Attribution License, which permits unrestricted use, distribution, and reproduction in any medium, provided the original work is properly cited.

This paper prepares polyethylene/silica nanocomposites with concentrations of $3 \mathrm{wt} \%$ and $5 \mathrm{wt} \%$ by using silicon dioxide $\left(\mathrm{SiO}_{2}\right)$ nanopowder (nanosilica) with particle sizes of 15 and $50 \mathrm{~nm}$. Samples whose elongations are 3\%, 6\%, and $10 \%$ are prepared. Pulsed electroacoustic technique is applied to evaluate the space charge distribution in samples. Test results show that homocharge near electrodes is generated in the polyethylene/silica nanocomposites. Nanocomposites with a nanoparticle concentration of $3 \mathrm{wt} \%$ and particle size of $15 \mathrm{~nm}$ suppress the accumulation of space charge effectively. The amount of space charge in the samples increases with the increase in elongation. At an elongation of $10 \%$, packet-like space charge is generated in polyethylene/silica nanocomposites with the concentration of $5 \mathrm{wt} \%$ and particle sizes of 15 and $50 \mathrm{~nm}$. The packet-like space charge in nanocomposites whose particle size is $50 \mathrm{~nm}$ is more obvious than that in nanocomposites whose particle size is $15 \mathrm{~nm}$. The experiment results are explained by applying interface characteristics, dipole model, and induced dipole model.

\section{Introduction}

The accumulation of space charge in polymer insulation makes a change of electric field. The electric field near the inner and outer semiconductive shielding layers becomes seriously distorted when a DC electric field on XLPE cables is applied because of the accumulation of space charge; this condition may cause accelerated aging $[1,2]$. Mechanical and electrical properties can be effectively improved through the use of nanomodified materials. The present study shows that the amount of space charge traps and the depths in polymer insulation can be reduced by adding nanoparticles, which may effectively minimize the accumulation of space charge and uniform electric field in polymer insulation [3-6].

Cables are inevitably affected by mechanical stress during manufacturing, transportation, installation, and operation. Such stress may cause the insulation materials of cables having elongation $[7,8]$. However, current research does not consider the elongation of insulation materials. Consequently, additional research on the electrical properties of polymer insulation during elongation should be conducted. With regard to insulation materials with an accumulation of space charge, there will be electrical trees by applying mechanical stress without electrical stress [9]. Research indicates that water tree in polymer insulation becomes serious when the cables' elongation is $6 \%$ under dynamic tensile stress at different frequencies [10]. The mechanical stress caused by the electric field is considered the reason for breakdown in polymer insulation [11]. Studies have confirmed that electrical and mechanical properties of polyethylene can be improved effectively by adding nanosilica. Similarly, the conclusion that the electrical properties of insulation may be affected by mechanical stress has been confirmed. However, research on the electrical properties of nanomodified materials during elongation is lacking. As such, more research on this area should be conducted.

In this study, polyethylene/silica nanocomposites with particle sizes of 15 and $50 \mathrm{~nm}$ and concentrations of $3 \mathrm{wt} \%$ and $5 \mathrm{wt} \%$ were prepared. Pulsed electroacoustic (PEA) technique was utilized to determine the characteristics of space charge in samples whose elongation is $3 \%$ and $6 \%$. The experiment results were explained by applying interface characteristics, dipole model, and induced dipole model. 


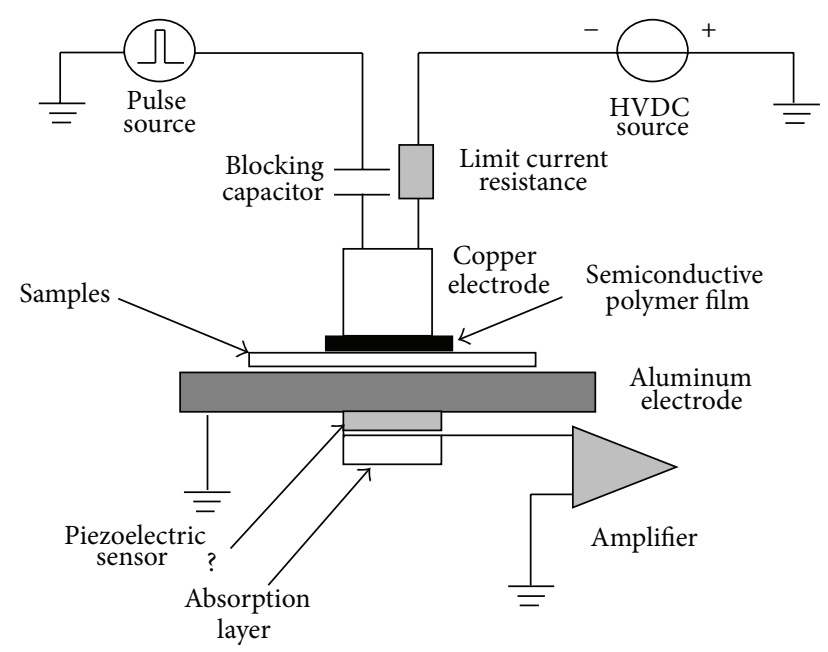

Figure 1: Schematic of the PEA device.

\section{Test Method}

2.1. Test Samples. Low density polyethylene (LDPE) materials produced by Lanzhou Petrochemical Company were selected and utilized. The model number of LDPE is $2426 \mathrm{H}$, the density is $0.910-0.925 \mathrm{mg} / \mathrm{cm}^{3}$, melt flow index is $2.1-$ $2.2 \mathrm{~g} / 10 \mathrm{~min}$, and the melting point is $112^{\circ} \mathrm{C}$. Nanometer material was produced by Shanghai Jingchun Scientific Co., Ltd. Mechanical blending method [12, 13] was applied to prepare the samples. The blending temperature is $120^{\circ} \mathrm{C}$, and the blending time is $30 \mathrm{~min}$. The sizes of nanoparticles are 15 and $50 \mathrm{~nm}$, and the concentrations are $3 \mathrm{wt} \%$ and $5 \mathrm{wt} \%$. The nanoparticles were dried in a vacuum dry oven for $24 \mathrm{~h}$ at $100^{\circ} \mathrm{C}$ and constant pressure. After blending, the materials were pressed into sheets in a flat vulcanizing machine at a temperature of $120^{\circ} \mathrm{C}$, time of $15 \mathrm{~min}$, and pressure of $12 \mathrm{MPa}$. The films, which were almost $0.19 \mu \mathrm{m}$, were cut into a dumbbell by using dumbbell tools and stressed in a tensile machine for $30 \mathrm{~min}$. The samples were degassed in a vacuum dry oven for $24 \mathrm{~h}$ at $80^{\circ} \mathrm{C}$ to eliminate residual stress.

2.2. PEA Technique. The space charge characteristics of polyethylene/silica nanocomposites were investigated with PEA technique. The PEA device is shown Figure 1.

In the PEA device, the output of the high-voltage direct current source ranges from 0 to $20 \mathrm{kV}$. The output of the pulse source ranges from 0 to $0.2 \mathrm{kV}$, the pulse width is $5 \mathrm{~ns}$, the frequency is $500 \mathrm{~Hz}$, and the thickness of the piezoelectric sensor is $25 \mu \mathrm{m}$. The upper electrode is a copper electrode, and the lower electrode is an aluminum one. The PEA device can communicate with computers by using a LeCory 7200 digital oscilloscope to collect the measuring signals. The resolution of PEA device is about $1.2 \times 10^{-3} \mathrm{C} / \mathrm{m}^{3}$.

2.3. Experimental Design. The samples were stressed by a negative DC voltage for $60 \mathrm{~min}$ (electric field of $30 \mathrm{kV} / \mathrm{mm}$ ). The space charge distribution was recorded at applied voltage times of 1, 10, 20, and $60 \mathrm{~min}$. A short-circuit dissipation test was then applied, and the distribution of space charge at 1, 5, 10 , and 20 min was recorded.

\section{Results}

3.1. Accumulative Characteristics of Space Charge. The space charge accumulation in an electric field of $30 \mathrm{kV} / \mathrm{mm}$ for polyethylene/silica nanocomposites with different elongations is shown in Figure 2.

There are heterocharges near positive and negative electrodes in the LDPE, as shown in Figure 2(a). By adding silica nanoparticles with a particle size of $15 \mathrm{~nm}$ and concentration of $3 \mathrm{wt} \%$, the heterocharges near the positive and negative electrodes almost disappeared, shown in Figure 2(e). This result proves that polyethylene/silica nanocomposites can suppress the accumulation of space charge. Obvious homocharge accumulation near positive and negative electrodes was observed in the insulation material when the silica nanoparticles' size was $15 \mathrm{~nm}$ and the concentration was $5 \mathrm{wt} \%$, shown in Figure $2(\mathrm{k})$. This result indicates that the addition of silica nanoparticles resulted in homocharge accumulation near positive and negative polarities. Compared with the polyethylene/silica nanocomposites whose particle size is $50 \mathrm{~nm}$, homocharge accumulation occurred when the concentration was only $3 \mathrm{wt} \%$, shown in Figure 2(i). Homocharge accumulation was more obvious in the polyethylene/silica nanocomposites when the concentration was $5 \mathrm{wt} \%$. We conclude that homocharge accumulation occurs near positive and negative polarities in a DC electric field when silica nanoparticles are added; an increase in particle size enhances this homocharge accumulation. Therefore, appropriate silica nanoparticles whose particle size is not extremely large should be selected in the production of polyethylene/silica nanocomposites.

According to Figure 2, there are more space charges near positive and negative electrodes for the nanocomposites whose elongation is $3 \%$ and $6 \%$ compared with the nanocomposites without elongation. As shown in Figures 2(b) and 2(c), the homocharge accumulation near positive and negative electrodes is the highest in the LDPE and the larger the elongation is, the more obvious the space charge accumulation is. For the polyethylene/silica nanocomposites whose particle size is $50 \mathrm{~nm}$, a packet-like space charge was observed in the nanocomposites when the elongation is $6 \%$.

To investigate the packet-like space charge in the nanocomposites, we prepared LDPE, polyethylene/silica nanocomposites with a particle size of $15 \mathrm{~nm}$ and concentration of $5 \mathrm{wt} \%$, and polyethylene/silica nanocomposites with a particle size of $50 \mathrm{~nm}$ and concentration of $5 \mathrm{wt} \%$ at an elongation of $10 \%$. The space charge characteristics are shown in Figure 3.

Comparison of the three images in Figure 3 shows that homocharge accumulation is more obvious and more space charges exist in the nanocomposites when the elongation is $10 \%$. However, no packet-like space charge was observed in the LDPE. When the particle size of the silica nanoparticles is $15 \mathrm{~nm}$ and the concentration is $5 \mathrm{wt} \%$, a packet-like space charge is created in the polyethylene/silica nanocomposites at an elongation of $10 \%$. For the polyethylene/silica nanocomposites whose particle size is $50 \mathrm{~nm}$ and concentration is $5 \mathrm{wt} \%$, a packet-like space charge was also created; 


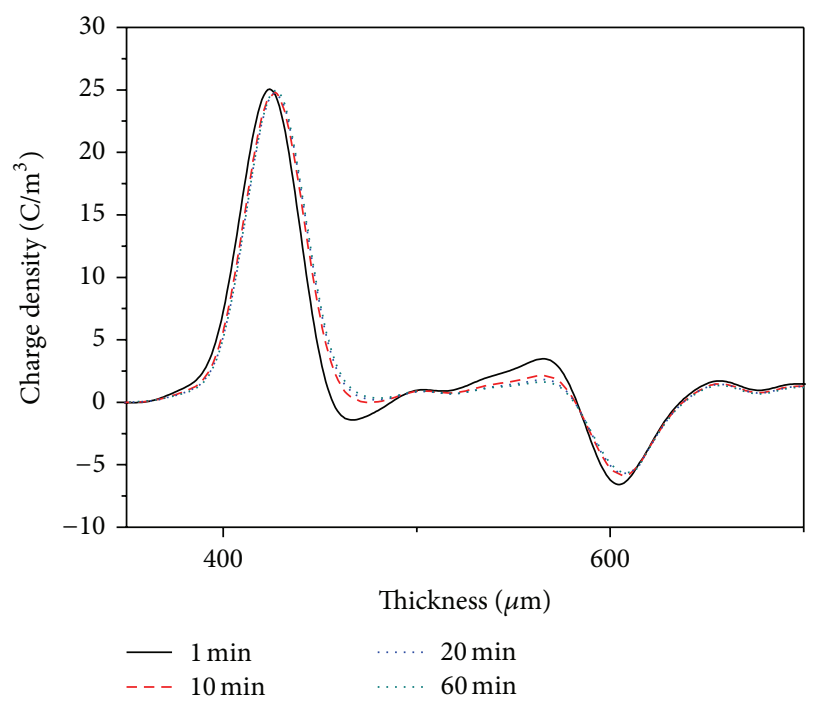

(a) LDPE

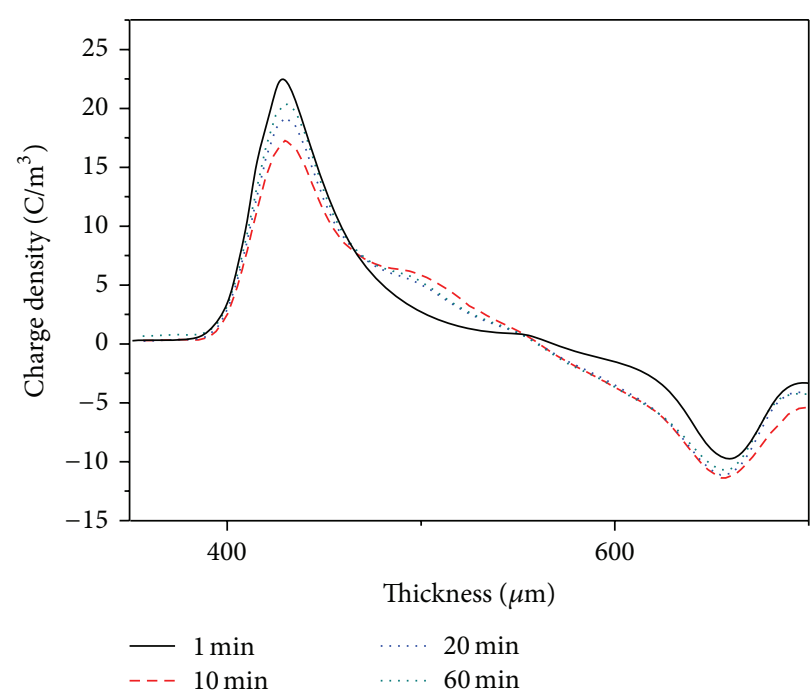

(c) LDPE with elongation of $6 \%$

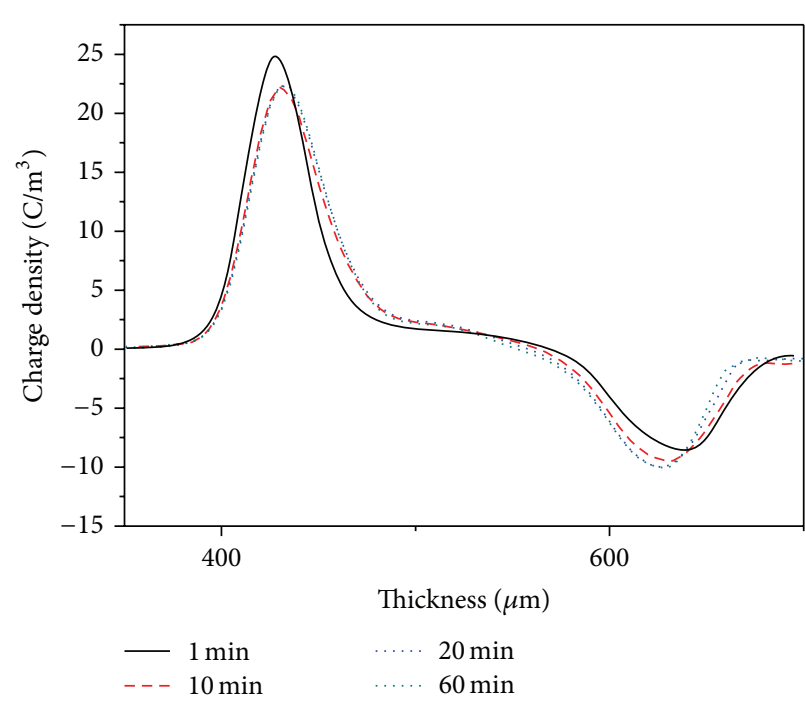

(e) $15 \mathrm{~nm}$; con is $3 \mathrm{wt} \%$ and elo is $3 \%$

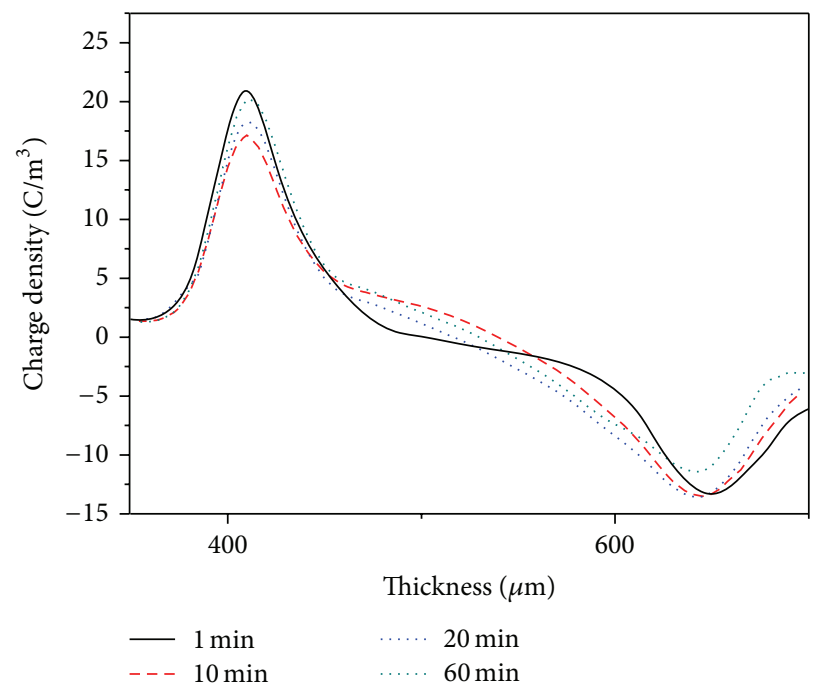

(b) LDPE with elongation of $3 \%$

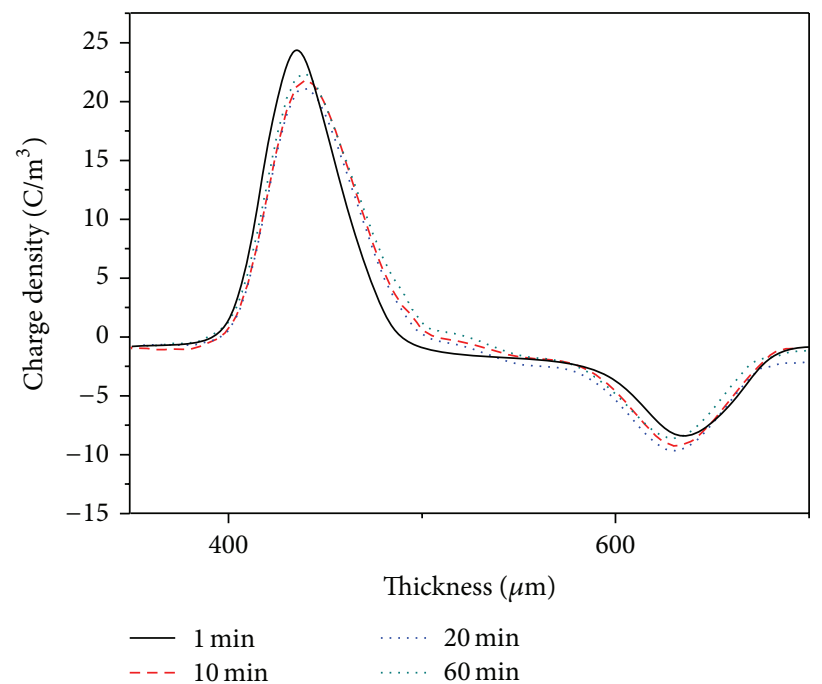

(d) $15 \mathrm{~nm}$; con is $3 \mathrm{wt} \%$

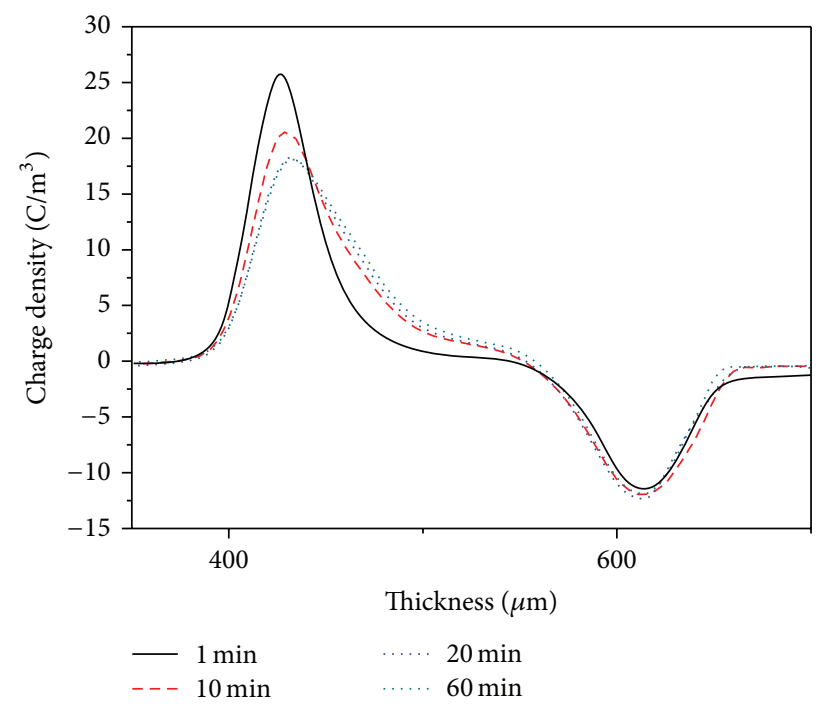

(f) $15 \mathrm{~nm}$; con is $3 \mathrm{wt} \%$ and elo is $6 \%$

FIgURE 2: Continued. 


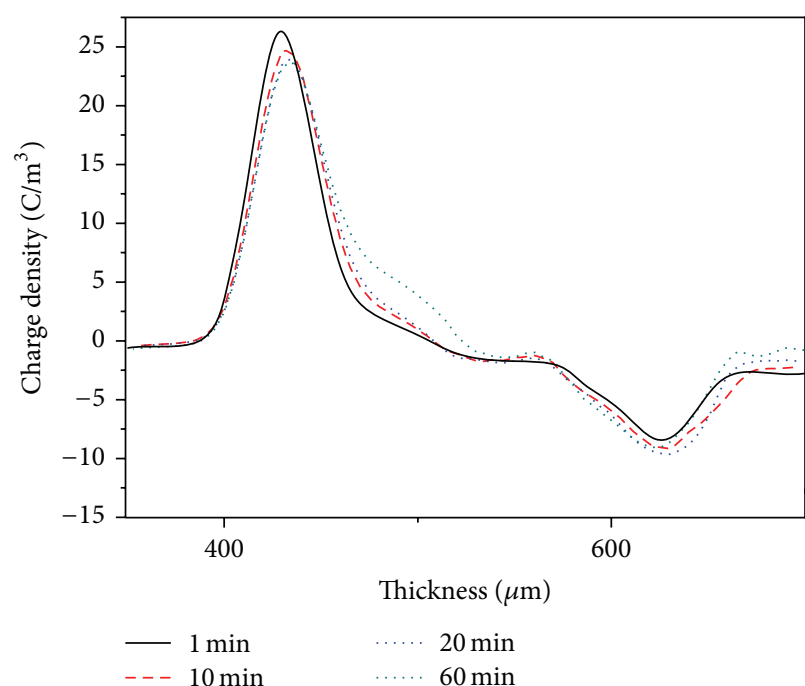

(g) $50 \mathrm{~nm}$; con is $3 \mathrm{wt} \%$

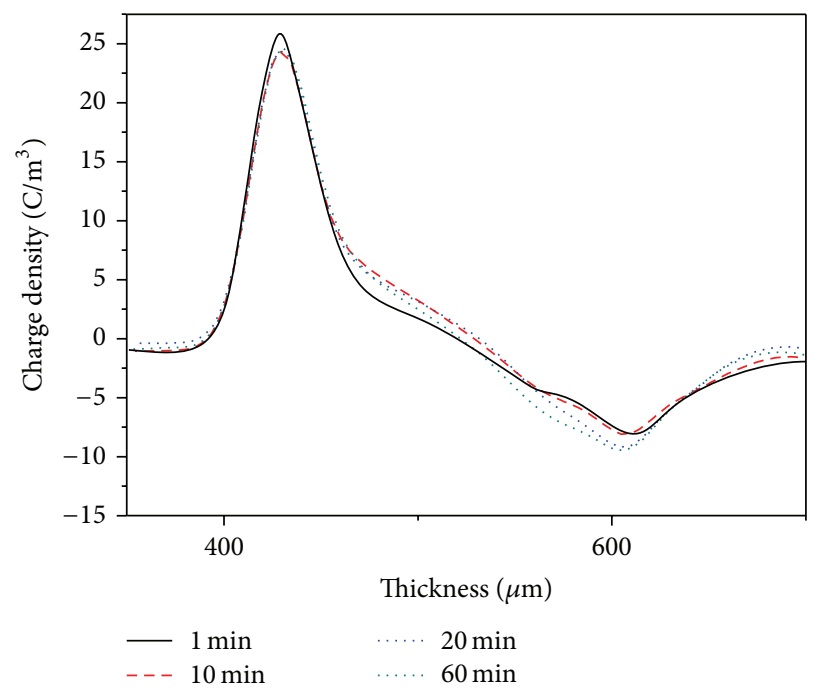

(i) $50 \mathrm{~nm}$; con is $3 \mathrm{wt} \%$ and elo is $6 \%$

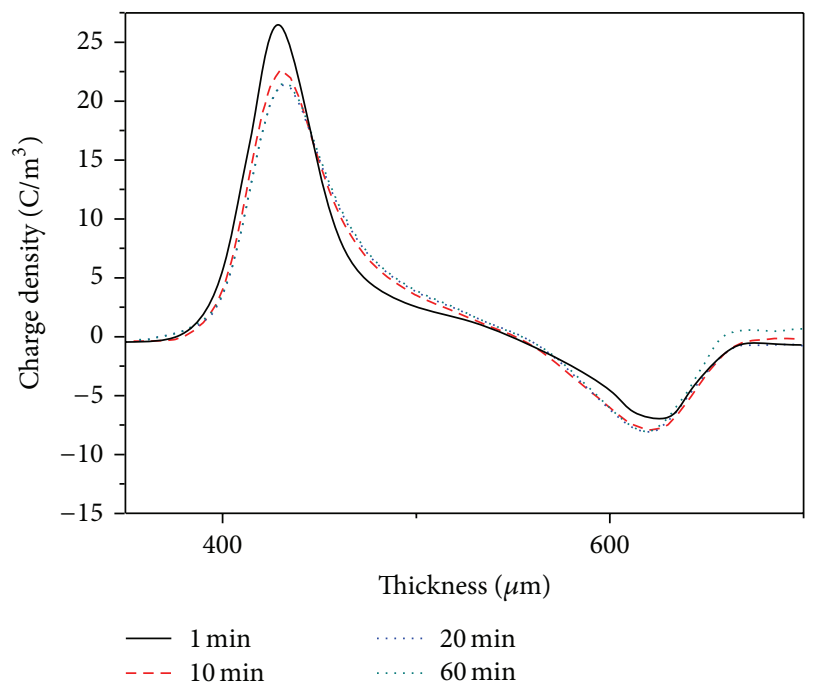

(k) $15 \mathrm{~nm}$; con is $5 \mathrm{wt} \%$ and elo is $3 \%$

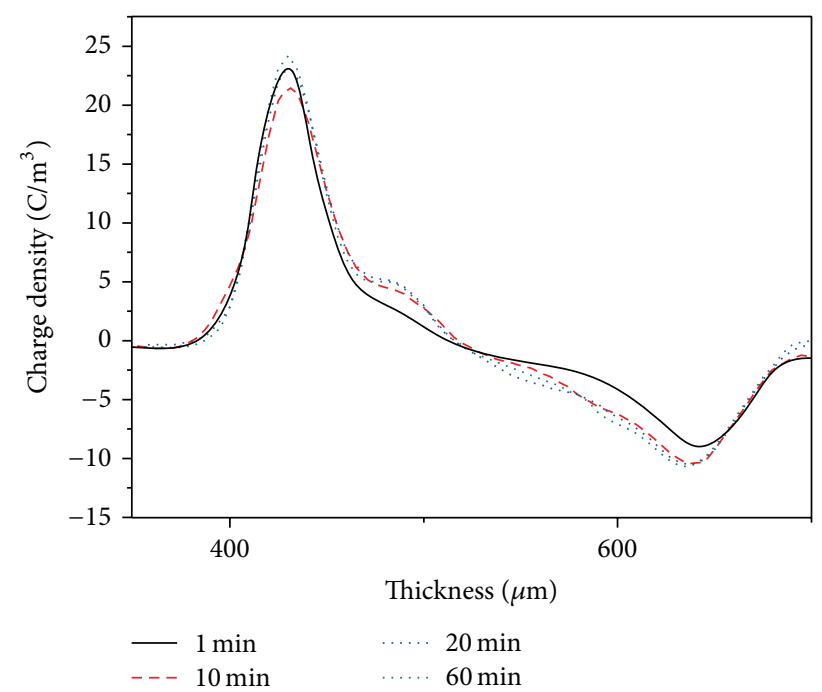

(h) $50 \mathrm{~nm}$; con is $3 \mathrm{wt} \%$ and elo is $3 \%$

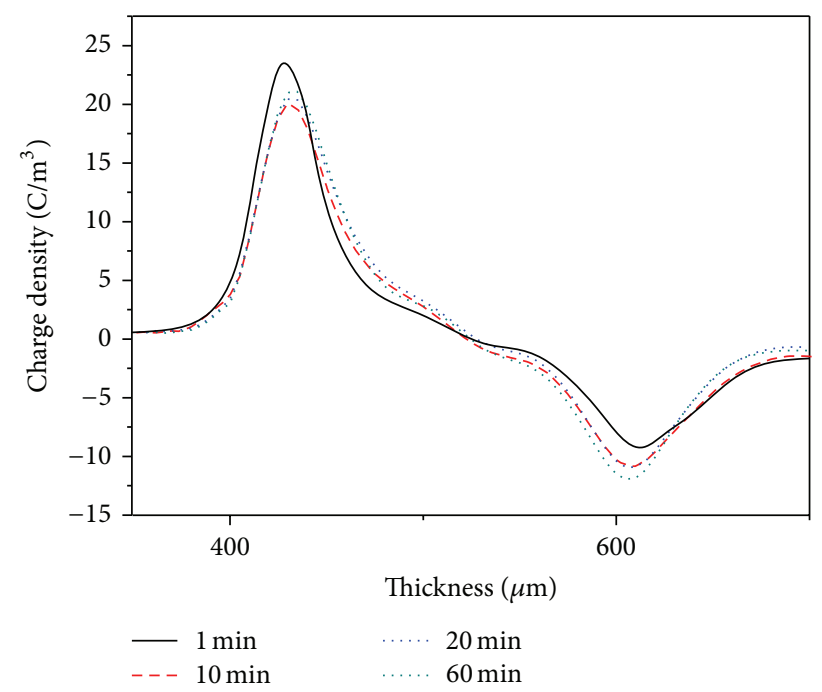

(j) $15 \mathrm{~nm}$; con is $5 \mathrm{wt} \%$

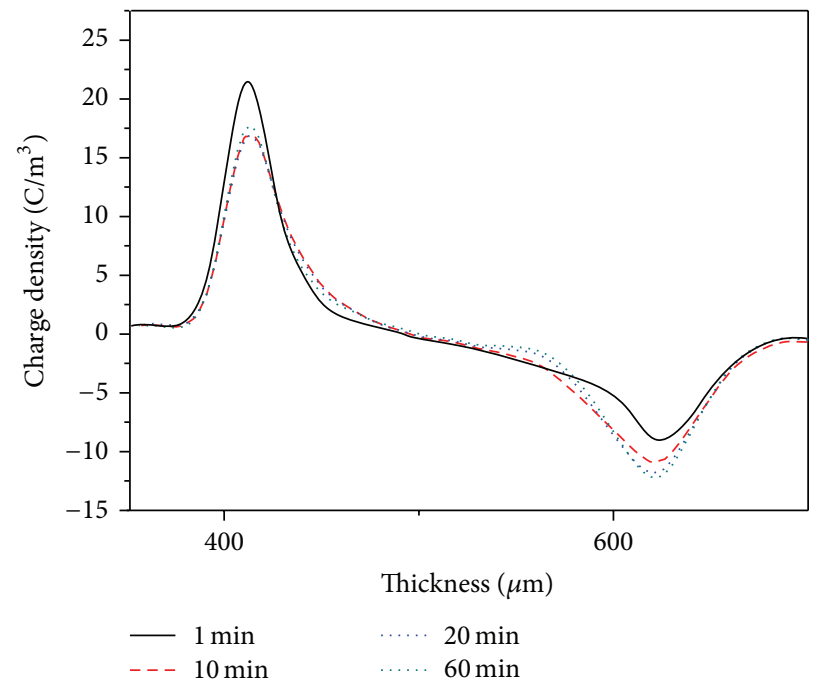

(l) $15 \mathrm{~nm}$; con is $5 \mathrm{wt} \%$ and elo is $6 \%$

FIGURE 2: Continued. 


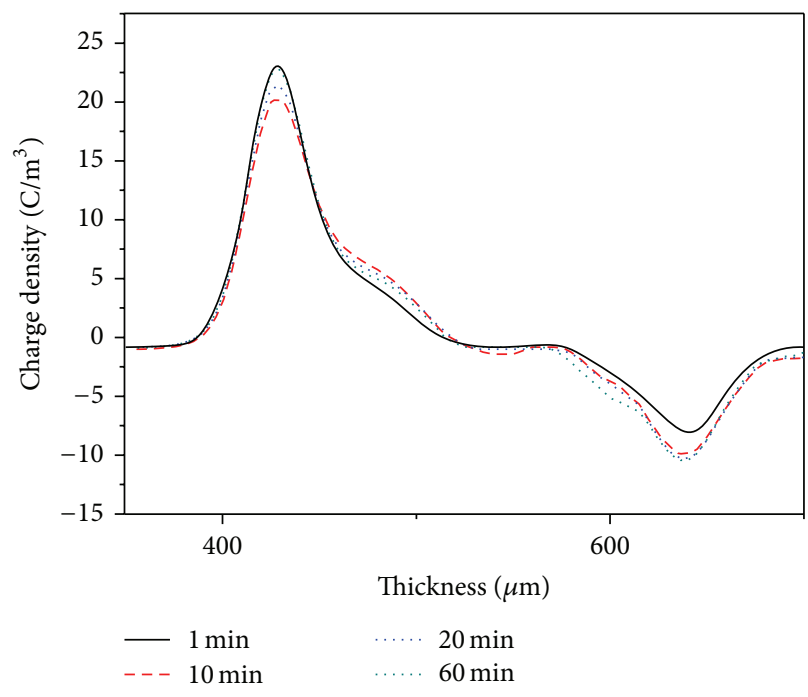

(m) $50 \mathrm{~nm}$; con is $5 \mathrm{wt} \%$

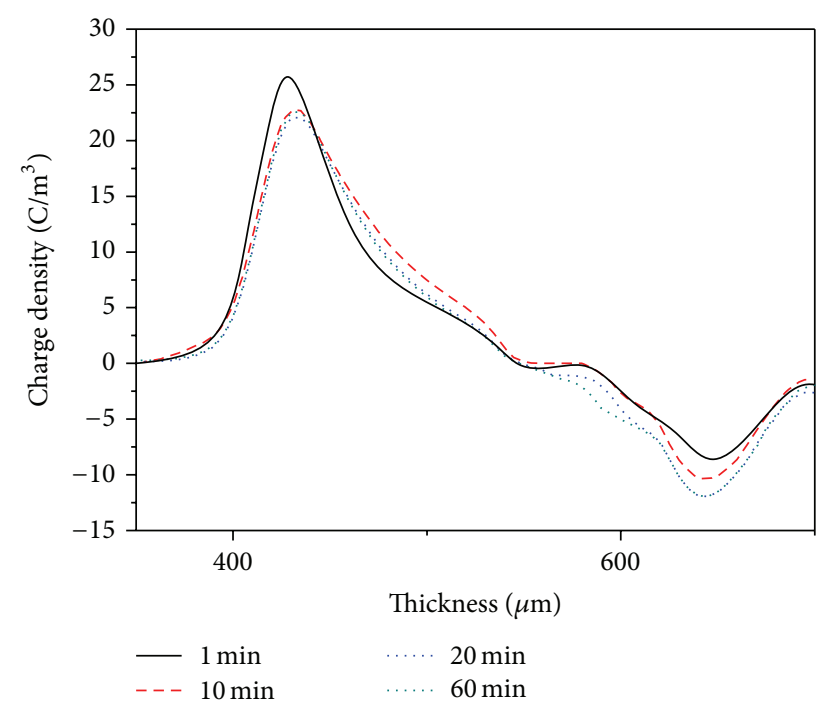

(n) $50 \mathrm{~nm}$; con is $5 \mathrm{wt} \%$ and elo is $3 \%$

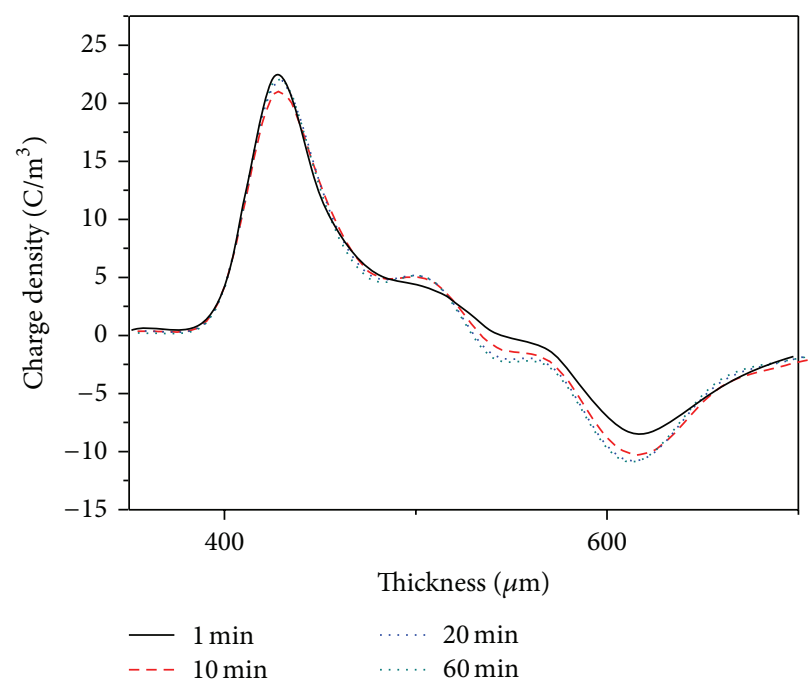

(o) $50 \mathrm{~nm}$; con is $5 \mathrm{wt} \%$ and elo is $6 \%$

FIGURE 2: Accumulative characteristics of space charge (con represents concentration and elo represents elongation).

the amount of space charge is more than that in the nanocomposites whose particle size is $15 \mathrm{~nm}$. In the nanocomposites with a packet-like space charge, less space charge between the packet-like space charge and electrodes was observed, which may be due to the mutual exclusion of homocharge.

Analyzing Figure 3(c), the packet-like space charges may fit Gaussian distributions. Calculating results shows that the packet-like space charge fits Gaussian distribution well when the time is $60 \mathrm{~min}$, as shown in Figure 4.

The expressions of Figures 4(a) and 4(b) are shown as (1) and (2), respectively:

$$
y=2.77+\left(\frac{140.06}{22.68 \times \sqrt{\pi / 2}} \times e^{-2 \times((x-514.23) / 22.68)^{2}}\right)
$$

$$
y=-6.57+\left(\frac{-78.83}{20.24 \times \sqrt{\pi / 2}} \times e^{-2 \times((x-563.74) / 20.24)^{2}}\right),
$$

where $x$ is position of space charge and $y$ is charge density.

According to the expressions, the widths of Gaussian distributions are almost equal, which represent the widths of packet-like space charge being very similar when time is $60 \mathrm{~min}$.

3.2. Detrapping Characteristics of Space Charge. The dissipation characteristics of space charge are shown in Figure 4.

Studies have shown that the addition of silica nanoparticles can effectively suppress the space charge in nanocomposites and change some of the deep traps into shallow traps. Analysis of Figures 5(a), 5(d), and 5(j) shows that less space charge exists in the nanocomposites whose particle size is $15 \mathrm{~nm}$ than in the LDPE when the charge detrapping 


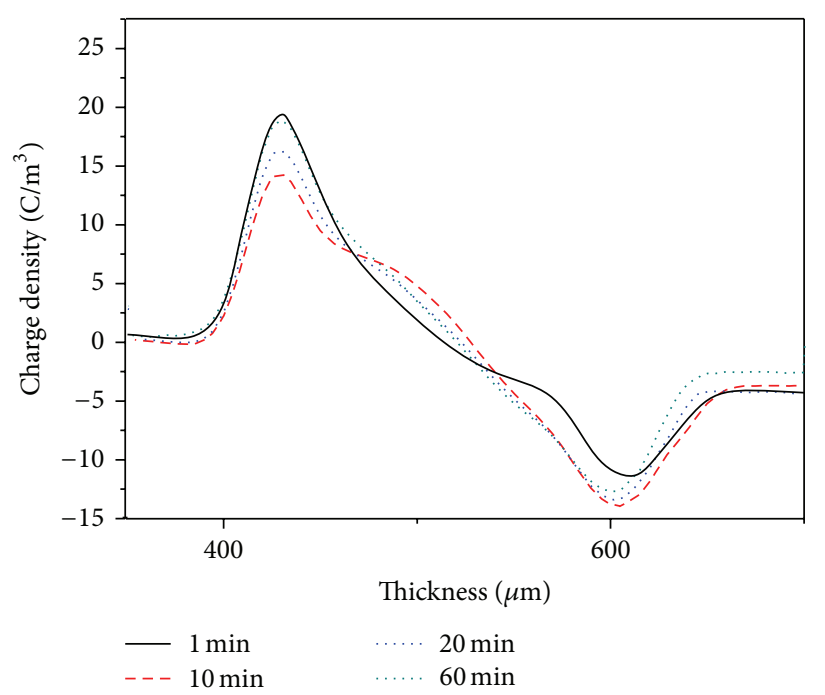

(a) LDPE

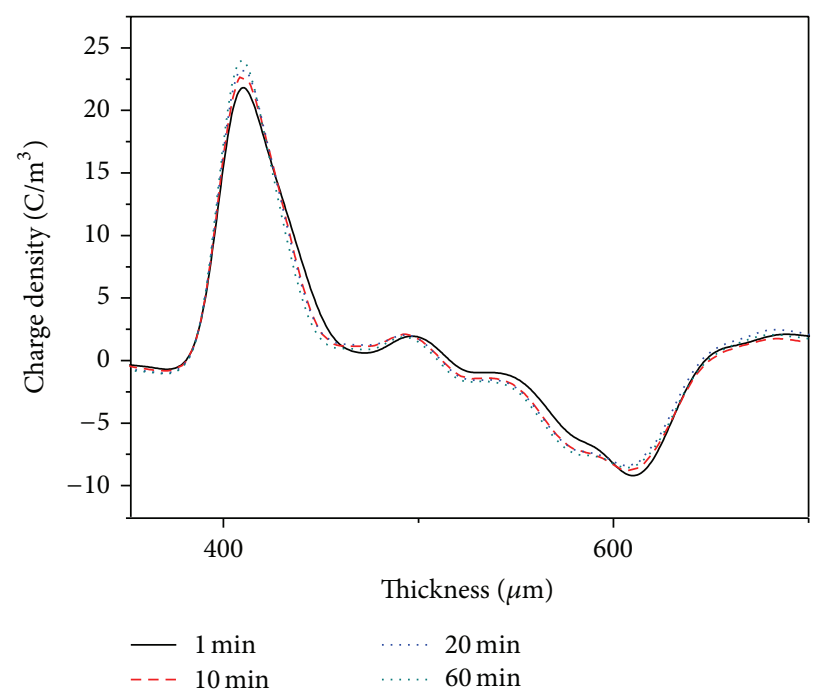

(b) $15 \mathrm{~nm}$; concentration is $5 \mathrm{wt} \%$

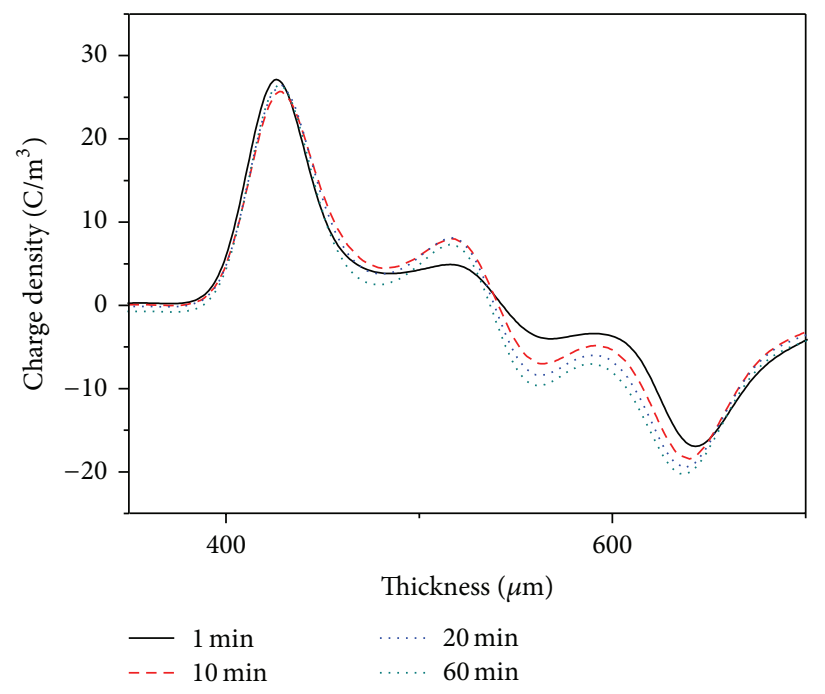

(c) $50 \mathrm{~nm}$; concentration is $5 \mathrm{wt} \%$

FIgURE 3: Accumulative characteristics of space charge with elongation of $10 \%$.

time is $1 \mathrm{~min}$. Moreover, its charge detrapping rate is higher than LDPE, and the remaining space charge is less. When the charge detrapping time is $1 \mathrm{~min}$, the amount of space charge in the nanocomposites whose particle size is $15 \mathrm{~nm}$ is less than the particle size of the silica nanoparticles which is $50 \mathrm{~nm}$, as shown in Figures 5(d), 5(g), 5(j), and $5(\mathrm{~m})$.

Comparison of the three insulation materials with different elongations shows that the charge detrapping rate is higher in the nanocomposites whose particle size is $15 \mathrm{~nm}$ than in the LDPE; the detrapping of space charge achieved stability within a short period of time. However, the charge detrapping time is longer in the nanocomposites whose particle size is $15 \mathrm{~nm}$ than others; these materials also required more time to reach stability. For the three materials, the amount of space charge is larger in the nanocomposites that are in elongation when the charge detrapping time is $1 \mathrm{~min}$.
With the increase in elongation, more space charges exist in the nanocomposites. Analysis of the curve whose charge detrapping time is $60 \mathrm{~min}$ shows that more deep traps are generated with the increase in elongation. Packet-like space charges are created in the polyethylene/silica nanocomposites whose particle size is $50 \mathrm{~nm}$ with elongation of $6 \%$. Moreover, packet-like space charges exist in the polyethylene/silica nanocomposites when the charge detrapping time is $60 \mathrm{~min}$. This result means that space charge accumulation is caused by deep traps in this section.

Comparison of the space charge characterisitcs of the three insulation materials in Figures 6 shows that the amount of space charge and deep traps is larger in the nanocomposites. Packet-like space charges exist in the polyethylene/silica nanocomposites whose particle size is $15 \mathrm{~nm}$ as a result of deep traps. Packet-like space charges also exist in the polyethylene/silica nanocomposites whose particle size is 


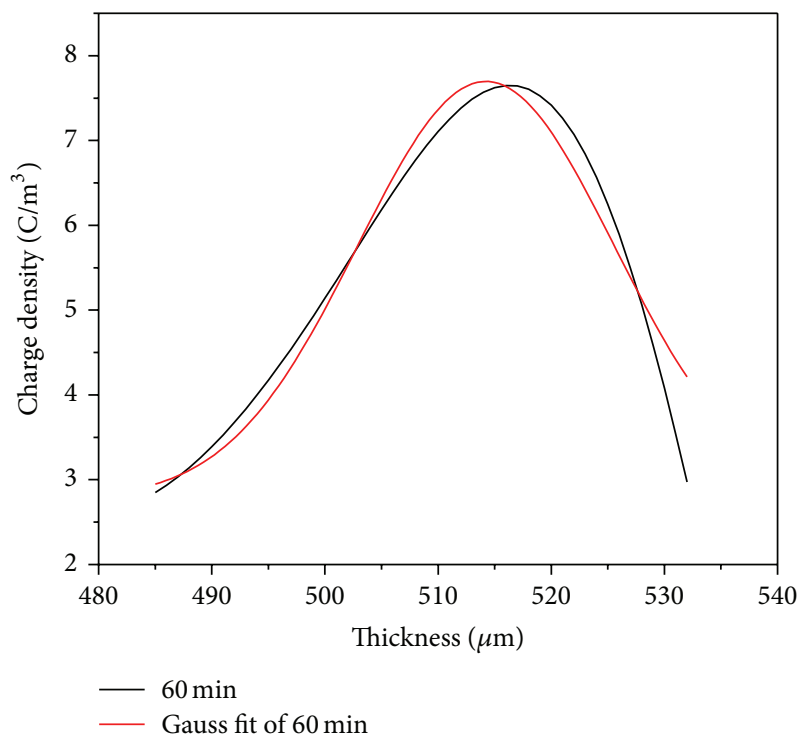

(a) Positive packet-like space charge

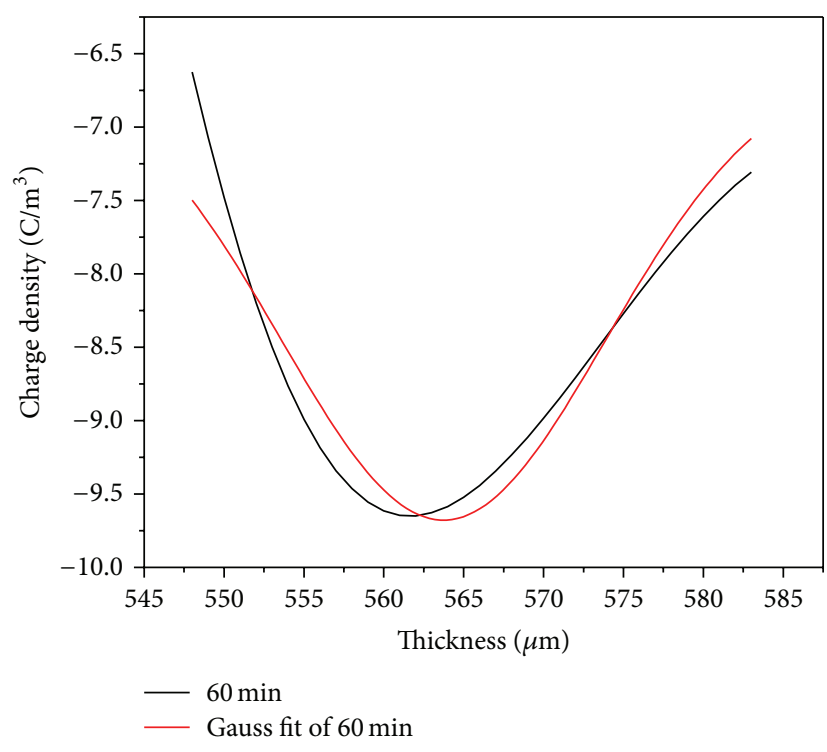

(b) Negative packet-like space charge

FIGURE 4: Fitting figure.

$50 \mathrm{~nm}$, which is more obvious than that in the nanocomposites whose particle size is $15 \mathrm{~nm}$; the dissipation rate is high in the packet-like space charges as a result of deep traps.

\section{Discussion}

4.1. Effect of Silica Nanoparticles on Space Charge in Polyethylene/Silica Nanocomposites. Space charge in the nanocomposites is mainly caused by two factors: characteristics of materials and the additives. Given that polymer consists of amorphous and crystalline regions, the interface characteristic between the crystalline and amorphous regions causes a large amount of traps, which may cause the accumulation of electrons and holes. The accumulation of space charge in the LDPE is mainly caused by the crystalline interface and internal defects of materials [14]. As inorganic nanoparticles are added to polymer, nanoparticles occupy the free volume in the material or defect and consequently reduce the amount of free volume and transform the deep traps into shallow traps. The addition of nanoparticles also creates a new interfacial layer between nanoparticles and polymer matrix, which has a significant effect on the electrical properties of nanocomposites. Several researchers believe that the characteristics of this interface can explain the change of properties of materials [15]. Therefore, more research on the interface characteristics of nanocomposites should be conducted.

An assumption is that nanoparticles are spherical and arranged in a simple cubic lattice. Calculation based on weight percent leads to the following expression [16]:

$$
D=\left\langle\left\{\frac{\pi}{6}\left(\frac{\rho_{n}}{\rho_{m}}\right) \frac{100}{M}\left[1-\frac{M}{100}\left(1-\frac{\rho_{n}}{\rho_{m}}\right)\right]\right\}^{1 / 3}-1\right\rangle d,
$$

where $\rho_{n}$ and $\rho_{m}$ are the specific gravity for the nanofiller and polymer matrix, respectively. $M$ is the weight fraction of nanofiller. $D$ is interfiller distance and $d$ is filler diameter.

The calculation expression of the surface area per unit volume is

$$
S=\frac{\pi d^{2}}{(D+d)^{3}}=\pi\left(\frac{d}{D+d}\right)^{2} \frac{1}{D+d}
$$

where $S$ is total surface area in unit volume.

According to (1) and (2), the distance between two nanoparticles is $158 \mathrm{~nm}$, and the total surface area in unit volume is $0.872 \mathrm{~km}^{2} / \mathrm{m}^{3}$ when the nanoparticles' size is $50 \mathrm{~nm}$ and the concentration is $5 \mathrm{wt} \%$. Similarly, the distance between two nanoparticles is $48 \mathrm{~nm}$ and total surface area in unit volume is $2.8 \mathrm{~km}^{2} / \mathrm{m}^{3}$ when the particle size is $15 \mathrm{~nm}$ and the concentration is $5 \mathrm{wt} \%$. We can see that the total surface area in unit volume is very large for the nanocomposites. The larger the particle size is, the larger the distance between particles is and the larger the total surface area in unit volume is.

Comparison of the space charge characteristics of LDPE and nanocomposites shows that the nanocomposites whose particle size is $15 \mathrm{~nm}$ and concentration is $3 \mathrm{wt} \%$ exhibit a significant suppression of space charge accumulation in the polyethylene/silica nanocomposites. This finding means the amount of traps caused by interface layer between silica nanoparticles and polymer matrix is smaller than the traps reduced by silica nanoparticles. Homocharge accumulations near positive and negative electrodes were observed in the polyethylene/silica nanocomposites when the sizes of the nanoparticles increase. More homocharges exist in the nanocomposites whose particle size is $50 \mathrm{~nm}$ than in the nanocomposites whose particle size is $15 \mathrm{~nm}$. These phenomena can be explained by interface layer characteristics. When 


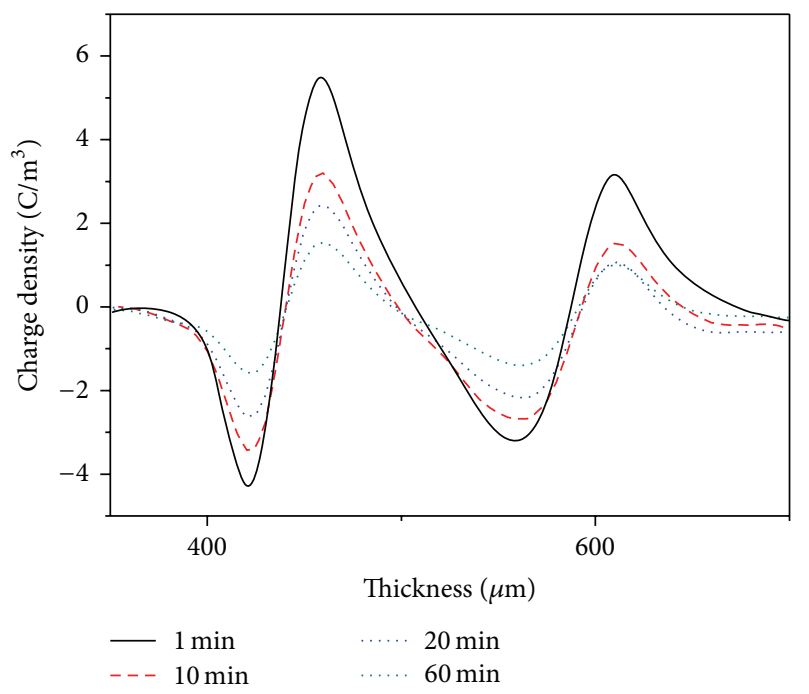

(a) LDPE

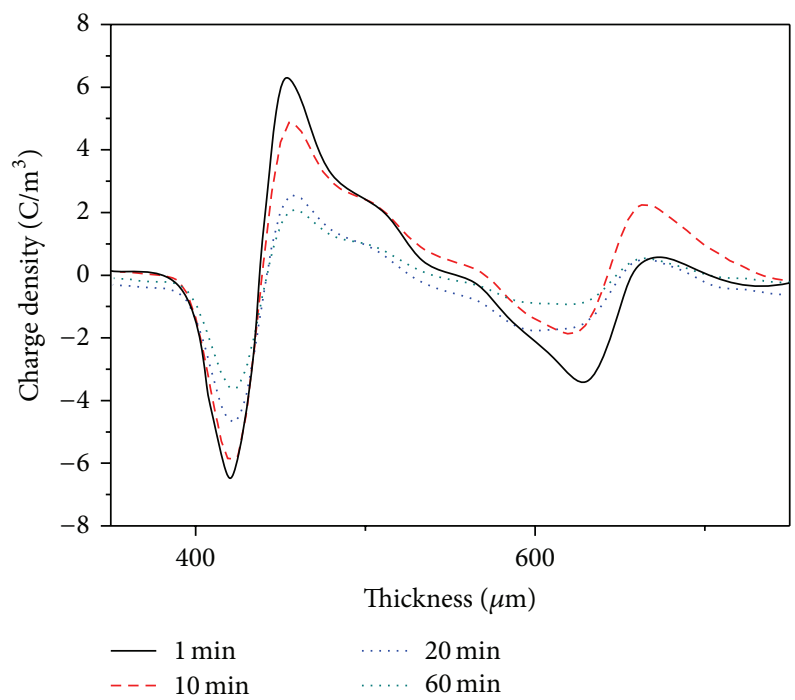

(c) LDPE with elongation of $6 \%$

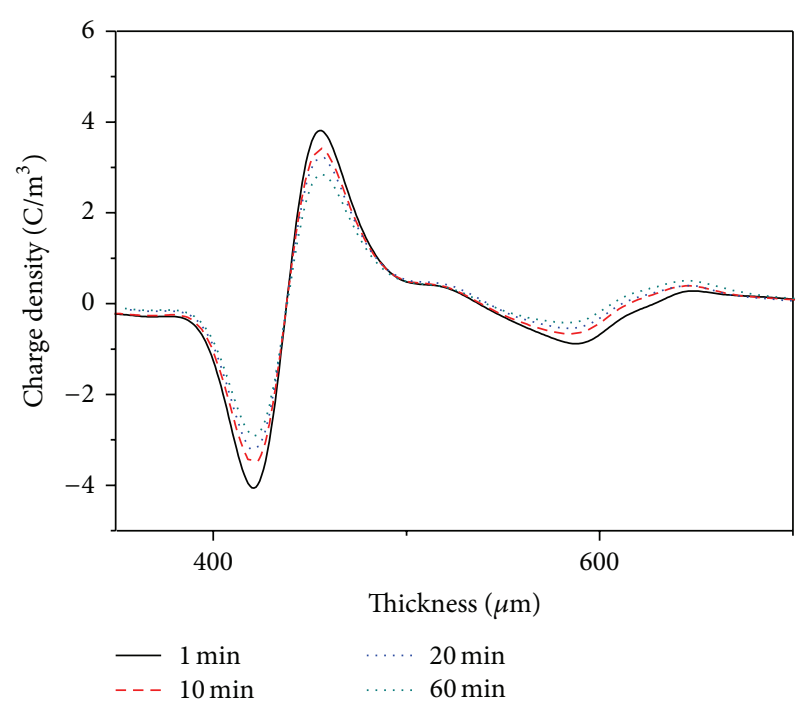

(e) $15 \mathrm{~nm}$; con is $3 \mathrm{wt} \%$ and elo is $3 \%$

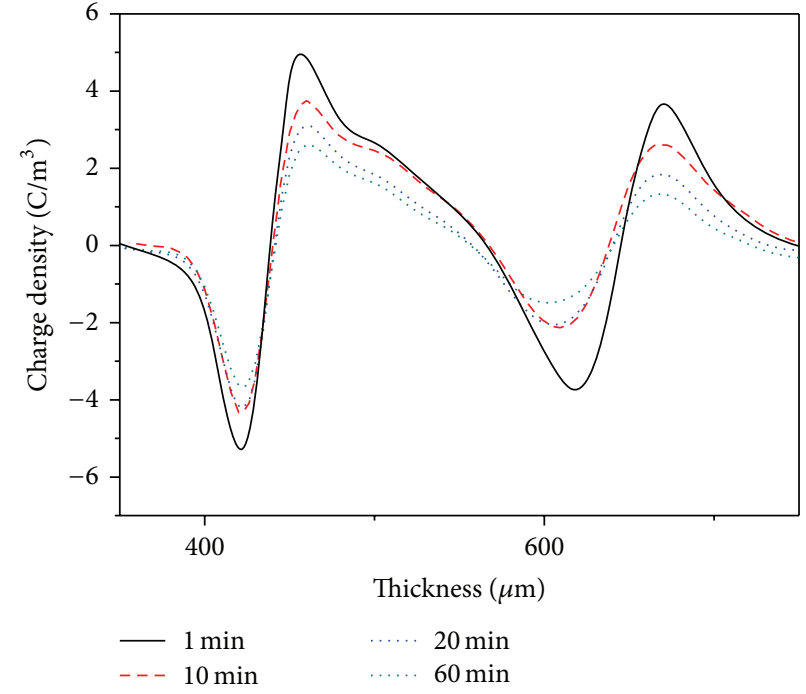

(b) LDPE with elongation of 3\%

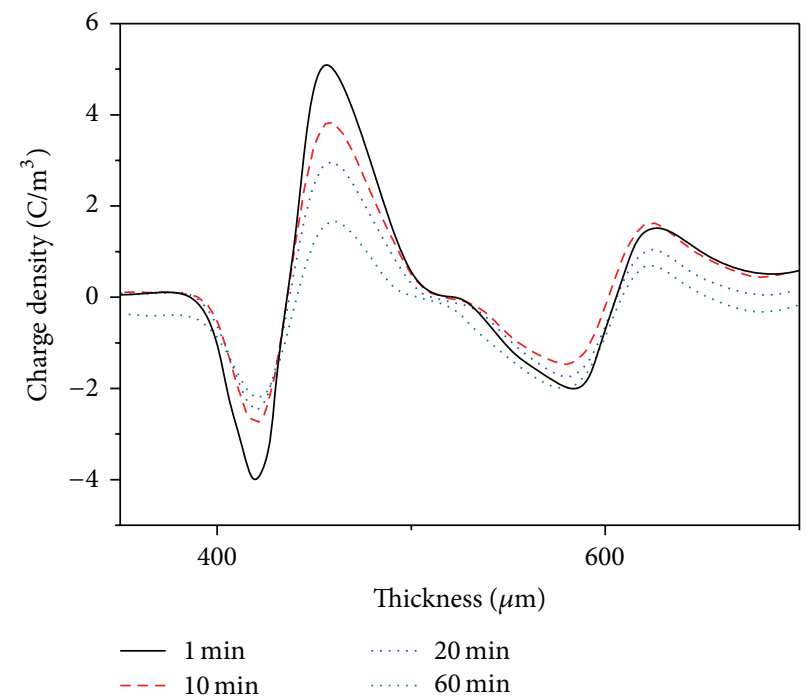

(d) $15 \mathrm{~nm}$; con is $3 \mathrm{wt} \%$

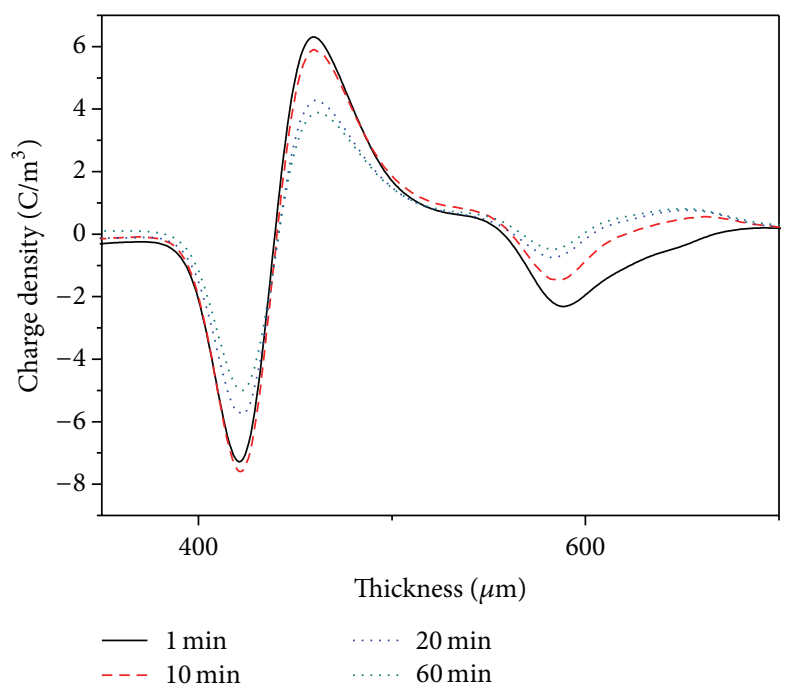

(f) $15 \mathrm{~nm}$; con is $3 \mathrm{wt} \%$ and elo is $6 \%$

Figure 5: Continued. 


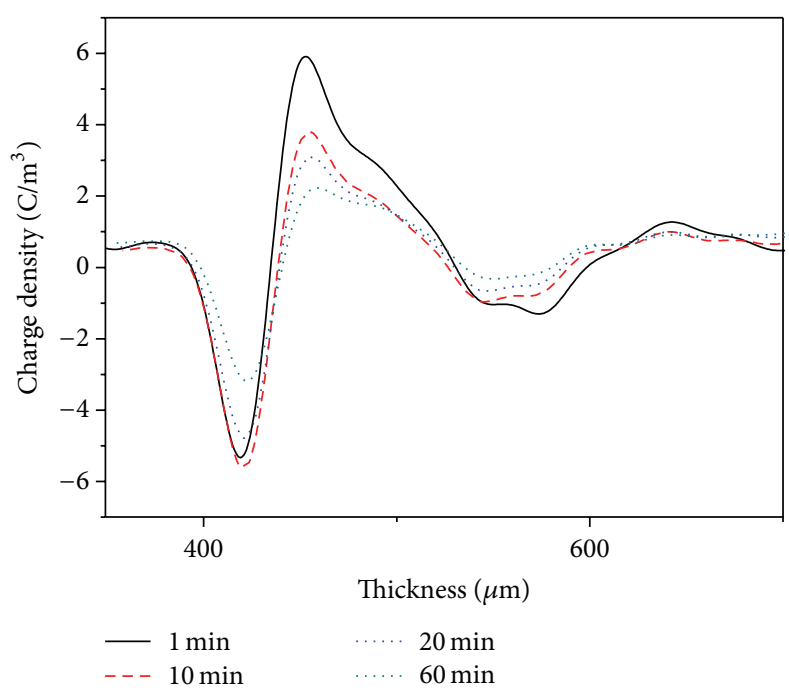

(g) $50 \mathrm{~nm}$; con is $3 \mathrm{wt} \%$

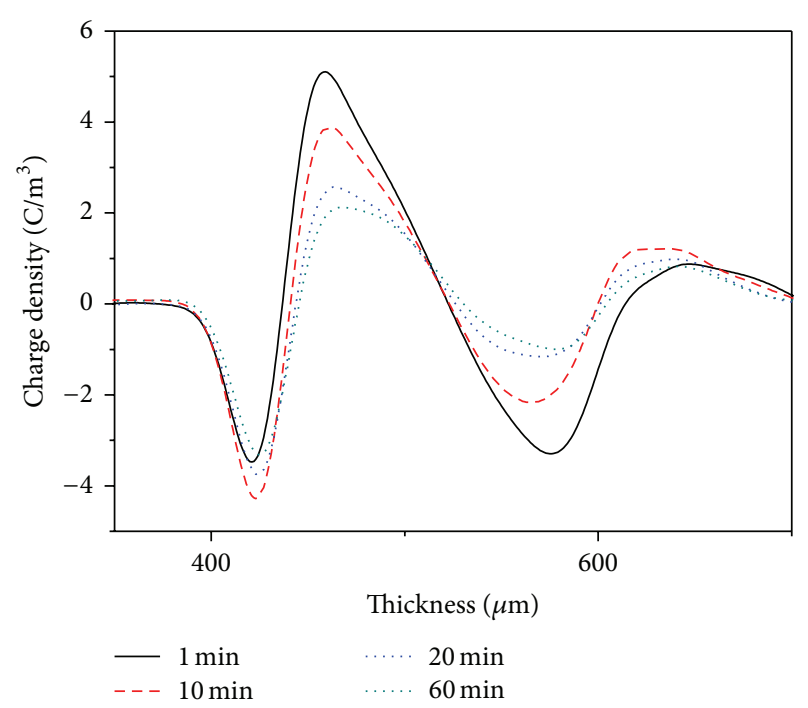

(i) $50 \mathrm{~nm}$; con is $3 \mathrm{wt} \%$ and elo is $6 \%$

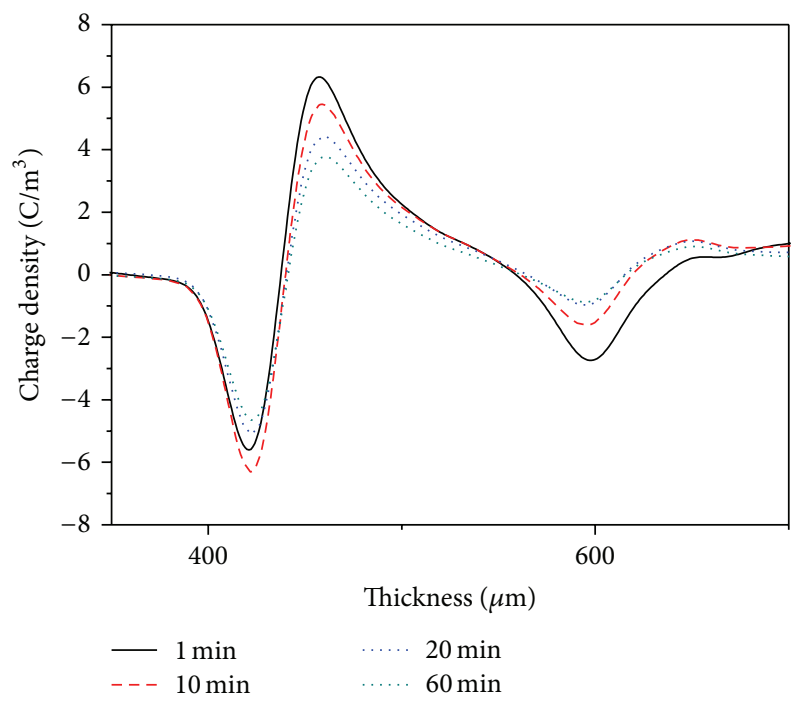

(k) $15 \mathrm{~nm}$; con is $5 \mathrm{wt} \%$ and elo is $3 \%$

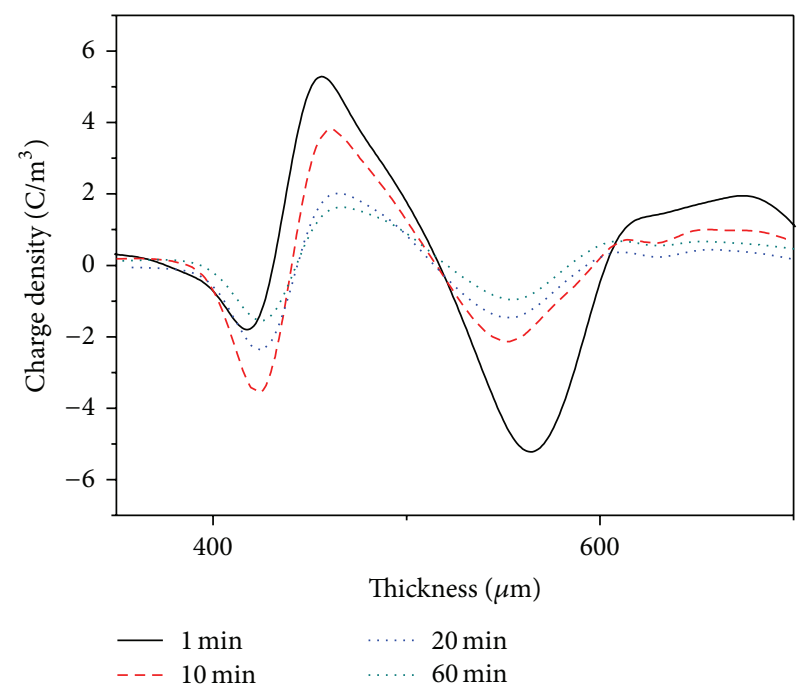

(h) $50 \mathrm{~nm}$; con is $3 \mathrm{wt} \%$ and elo is $3 \%$

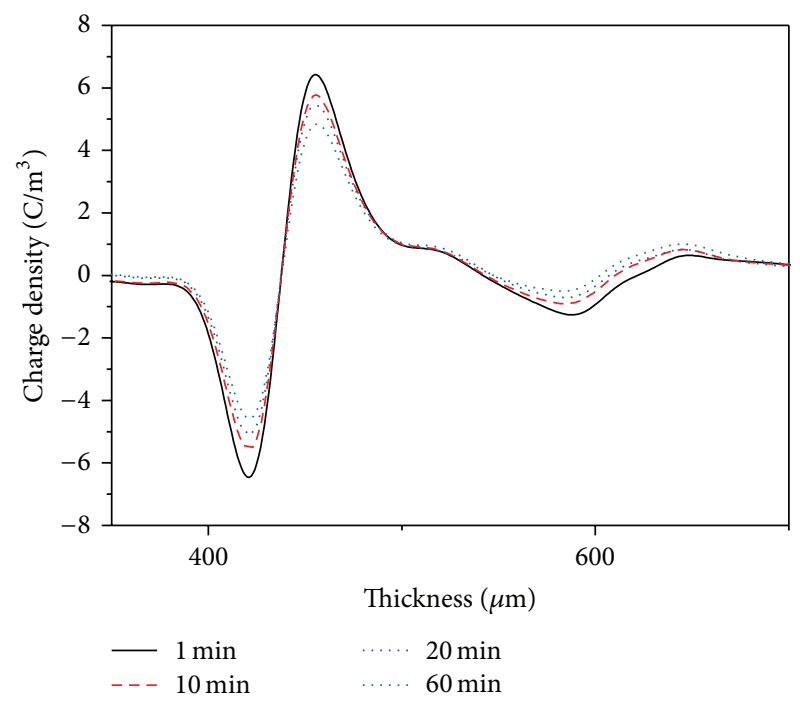

(j) $15 \mathrm{~nm}$; con is $5 \mathrm{wt} \%$

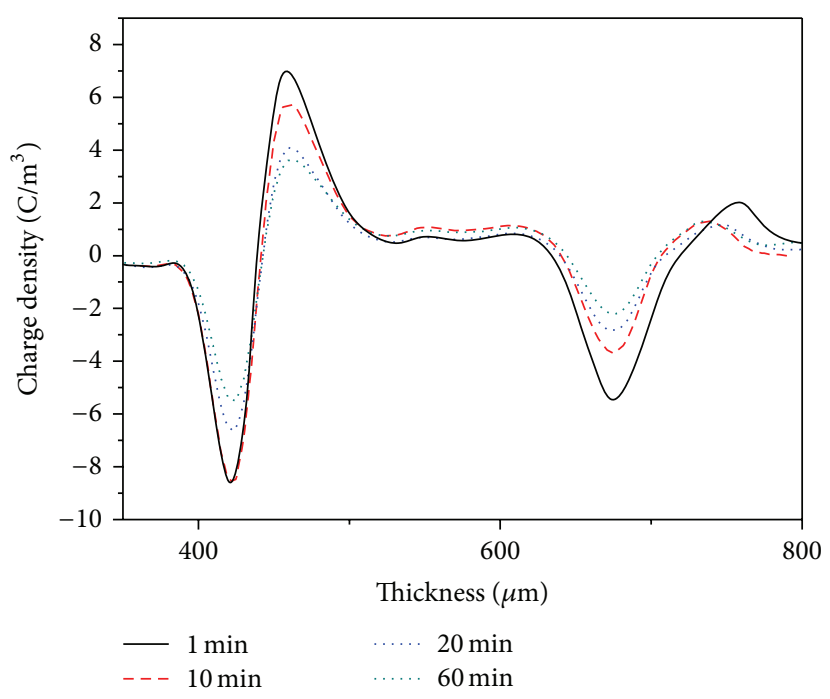

(l) $15 \mathrm{~nm}$; con is $5 \mathrm{wt} \%$ and elo is $6 \%$

Figure 5: Continued. 


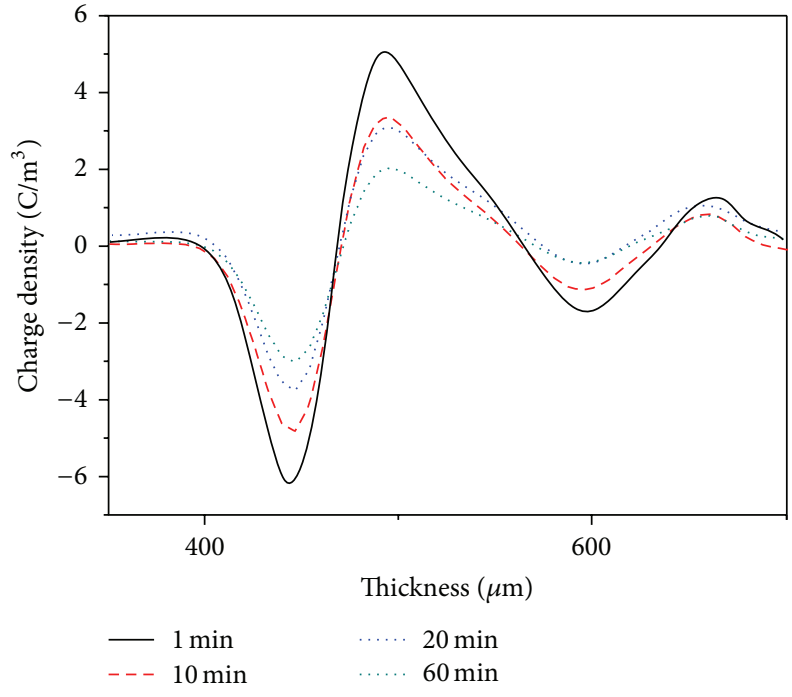

(m) $50 \mathrm{~nm}$; con is $5 \mathrm{wt} \%$

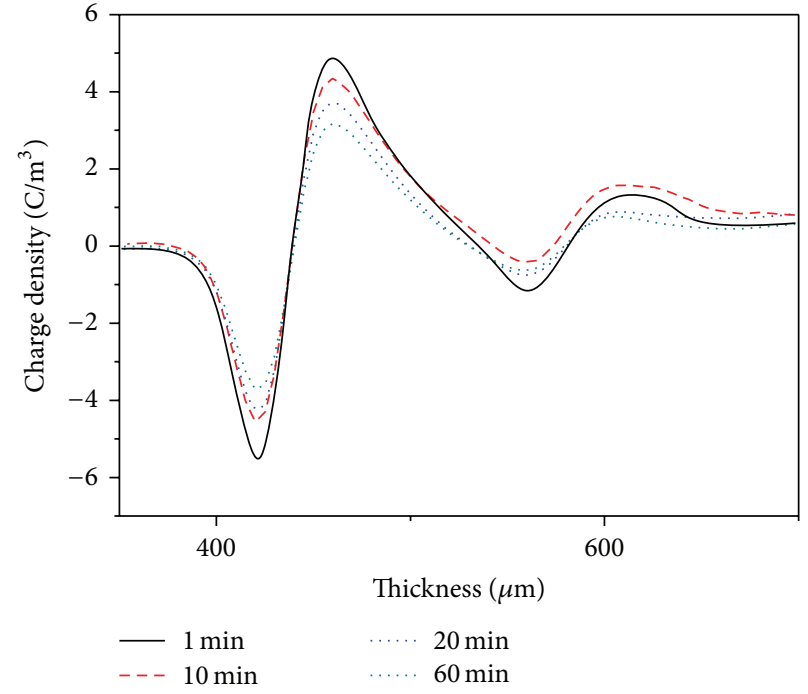

(n) $50 \mathrm{~nm}$; con is $5 \mathrm{wt} \%$ and elo is $3 \%$

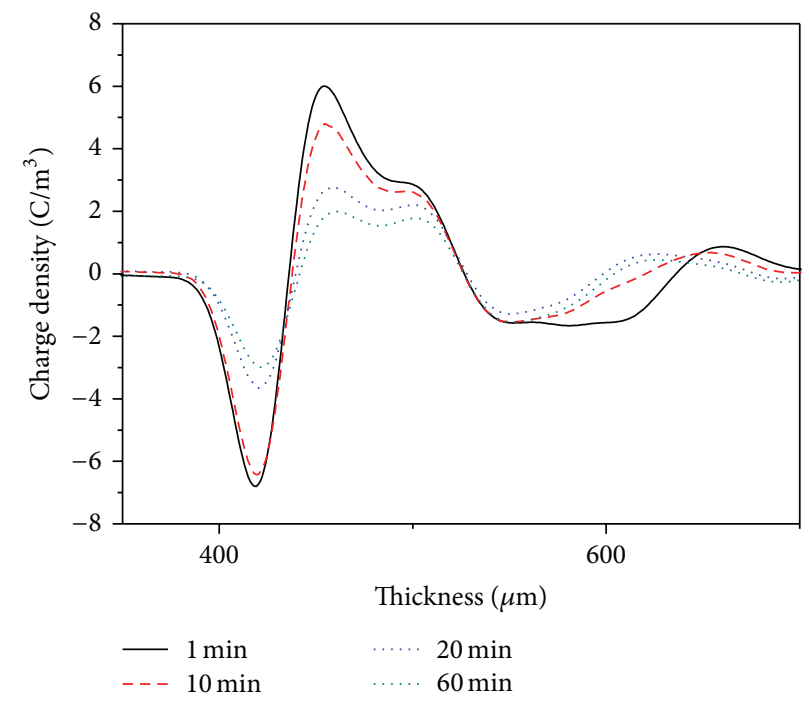

(o) $50 \mathrm{~nm}$; con is $5 \mathrm{wt} \%$ and elo is $6 \%$

FIGURE 5: Detrapping characteristics of space charge (con represents concentration and elo represents elongation).

the particle size or concentration of nanoparticles is large, the total surface area in unit volume and the interface layer between nanoparticles and polymer matrix are also large. Therefore, the amount of space charge traps caused by the interface layer is also large, which makes the amount of space charge in the nanocomposites whose particle size is $50 \mathrm{~nm}$ become larger than that in the nanocomposites whose particle size is $15 \mathrm{~nm}$.

A slightly obvious phenomenon was observed by analyzing the space charge characteristics of all nanocomposites, as shown in Figures 2(d), 2(g), and 2(j). The total amount of space charge accumulated near positive electrodes is larger than the space charge accumulated near negative electrodes in the nanocomposites. Triboelectricity can explain this phenomenon. According to the research of Tanaka et al. [16], triboelectricity exists in nanocomposites during the preparation process. Nanocomposites are negatively charged, which may repel electrons. Of course, the effect of triboelectricity on the mobility of space charge is small and insignificant.

4.2. Effect of Elongation on Space Charge in Polyethylene/Silica Nanocomposites. No definite conclusions have been established regarding the status of nanoparticles in nanocomposites. The mode of action between nanoparticles and polymer matrix, the status of space charge traps in nanocomposites, and the inhibiting effect of nanoparticles on space charge remain unclear. According to the research of Takada et al. [17], many carbonyl $(\mathrm{C}=\mathrm{O})$ and hydroxyl $(\mathrm{OH})$ defects exist in polymer; this existence may generate dipoles in a DC electric field which may cause dipole moments and electrical potential distribution. Electrical potential distribution can be regarded as space charge traps, and the value of the electric potential can be viewed as the depth of space 
charge traps, to a certain extent. Takada et al. calculated the electrical potential distribution caused by dipoles. Their assumption was that the charge of carbonyl $(\mathrm{C}=\mathrm{O})$ and hydroxyl $(\mathrm{OH})$ defects is $q$ in polymer, and the distance between two dipoles is $l$. The diploe moments can be calculated by $m=q * l$. The electrical potential distribution, $V(r, \theta, \phi)$, is provided by (3) in spherical coordinates. Consider

$$
V(r, \theta, \phi)=\frac{m \cos \phi}{\varepsilon_{0} \varepsilon_{r} 4 \pi r^{2}} \sin \theta,
$$

where $m$ is dipole moment, $\varepsilon_{0}$ is absolute dielectric constant, $\varepsilon_{r}$ is relative dielectric of polymer, and $\phi$ and $\theta$ represent spherical coordinates.

According to the test results of this study, as shown in Figure 2, the amount of space charge increases with the increase in elongation in the LDPE and nanocomposites. When the nanocomposites are in elongation, the distance between carbonyl $(\mathrm{C}=\mathrm{O})$ and hydroxyl $(\mathrm{OH})$ defects is large. According to (3), the electrical potential distribution increases with the increase in distance $l$. This result indicates that the depth of space charge increases in nanocomposites. Therefore, the amount of space charge and deep traps increases.

According to the space charge characteristics of LDPE, as shown in Figure 3(a), the amount of space charge is larger near the electrodes than in the interior, which is roughly a trapezoidal decline. This result means that the surface of the LDPE may be vulnerable to elongation and carbonyl $(\mathrm{C}=\mathrm{O})$ and hydroxyl $(\mathrm{OH})$ defects; the surface may has a larger elongation than the interior.

4.3. Packet-Like Space Charge. Small packet-like space charges were observed near positive and negative polarities in the polyethylene/silica nanocomposites whose particle size is $15 \mathrm{~nm}$ and concentration is $5 \mathrm{wt} \%$ when elongation is $10 \%$. More obvious packet-like space charges were observed near positive and negative polarities in the polyethylene/ silica nanocomposites whose particle size is $50 \mathrm{~nm}$. The packet-like space charges are caused by deep traps in the polyethylene/silica nanocomposites, as revealed by the analysis of the dissipation characteristics. These phenomena can be explained from two aspects.

For polyethylene/silica nanocomposites, the assumption is that nanoparticles are spherical and the electric field is uniform. Hence, a certain amount of induction charges, which can be induced dipoles, exists at the surface of nanoparticles. Similarly, induced dipole moments and induction electromotive force exist. The surface charge density of dipole is [17]

$$
\sigma_{p}=\varepsilon_{0} E_{0}\left(1-\frac{3 \varepsilon_{r 1}}{2 \varepsilon_{r 1}+\varepsilon_{r 2}}\right) \cos \phi^{\prime} \sin \phi^{\prime},
$$

where $\varepsilon_{0}$ is absolute dielectric constant, $\varepsilon_{r 1}$ is dielectric constant of polymer, and $\varepsilon_{r 2}$ is dielectric constant of filler; $\phi^{\prime}$ represent spherical coordinates.
The electrical potential distribution, $V(r, \theta, \phi)$, is provided by (4) in spherical coordinates [17]. Consider

$$
\begin{aligned}
& \frac{V(r, \phi)}{a E_{0}} \\
& =\frac{1}{4 \pi}\left[1-\frac{3 \varepsilon_{r 1}}{2 \varepsilon_{r 1}+\varepsilon_{r 2}}\right] \\
& \quad \times \int_{-\pi}^{+\pi} \int_{0}^{+\pi} \frac{\sin ^{2} \theta^{\prime} d \theta^{\prime} \cos \phi^{\prime} d \phi^{\prime}}{\sqrt{1+(r / a)^{2}-2(r / a) \sin \theta^{\prime} \cos \left(\phi-\phi^{\prime}\right)}}
\end{aligned}
$$

where $\varepsilon_{0}$ is absolute dielectric constant, $\varepsilon_{r 1}$ is dielectric constant of polymer and $\varepsilon_{r 2}$ is dielectric constant of filler, $a$ is radius of particles, $E_{0}$ is external field, and $r, \theta^{\prime} \phi^{\prime}, \phi$ represent spherical coordinates and more details are shown in $[17$, Figure 6].

When an external field $E_{0}$ is applied to the nanocomposites, we can assume that the surface charge induced by $E_{0}$ is positive on silicon atom and it is negative on oxygen atom. At the same time, because of the bond strength between silicon atom and oxygen atom, as the nanocomposites with elongation, the bond length of silicon atom and oxygen atom changes slightly. Therefore, the nanoparticles in polymer stressed by tensile force can also be supposed to be spherical whose diameter is larger than nanoparticles in polymer without tensile force. So (4) and (5) can also be appropriate. According to (5), relationships exist between electrical potential distribution and diameter of nanoparticles. This relationship means that when the diameter of nanoparticles is large, the electrical potential distribution and the depth of the space charge traps increase [17]. Therefore, stressed by tensile force, the space charge traps caused by electrical potential distribution change from shallow traps to deep traps. So it explains why there are more space charges in nanocomposites with elongations, which may induce packet-like space charge, as shown in Figures 3(b) and 3(c).

For the nanocomposites whose particle size is 15 and $50 \mathrm{~nm}$, the diameter of nanoparticles increases with the increase in particle size. Therefore, according to (5), the electrical potential distribution of nanocomposites whose particle size is $50 \mathrm{~nm}$ is larger than nanocomposites whose particle size is $15 \mathrm{~nm}$, which indicates that very obvious packetlike space charges exist in polyethylene/silica nanocomposites comparing with the polyethylene/silica nanocomposites whose particle size is $15 \mathrm{~nm}$ with small packet-like space charges, as shown in Figures 3(b) and 3(c).

However, the induced dipole model cannot completely explain the packet-like space charges. For the nanocomposites, no definite conclusion exists with regard to the types of force between nanoparticles and polymer matrix, which may be Van Edward force, covalent bond, molecular bond, or others. Several researchers believe that the type of force is a hydrogen bond in nanocomposites, which are prepared by mechanical blending [16]. Other researchers believe that the type of force is a covalent bond when vinylsilane is utilized to modify the interface of silica nanoparticles [18]. Considering the interface layer between nanoparticles and 


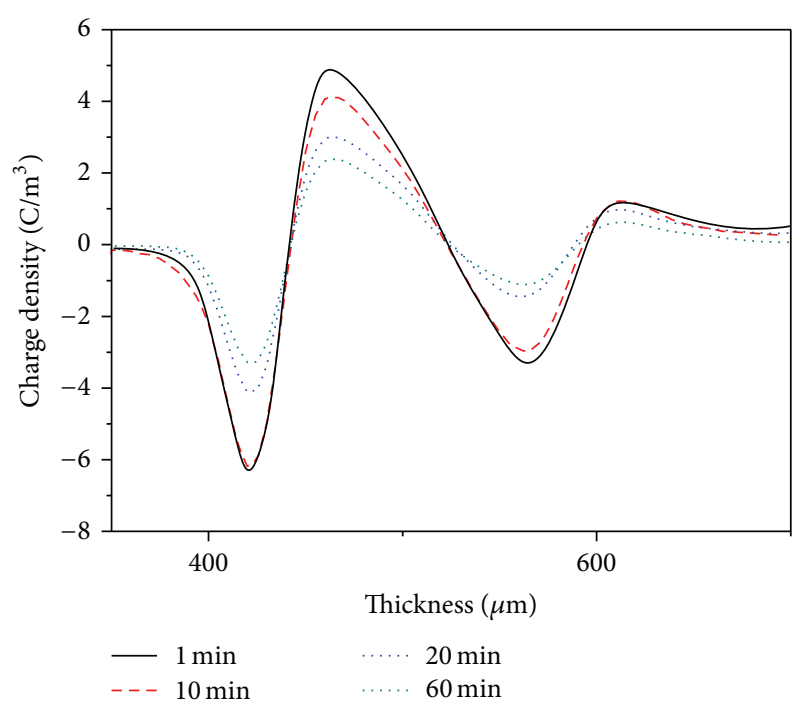

(a) LDPE

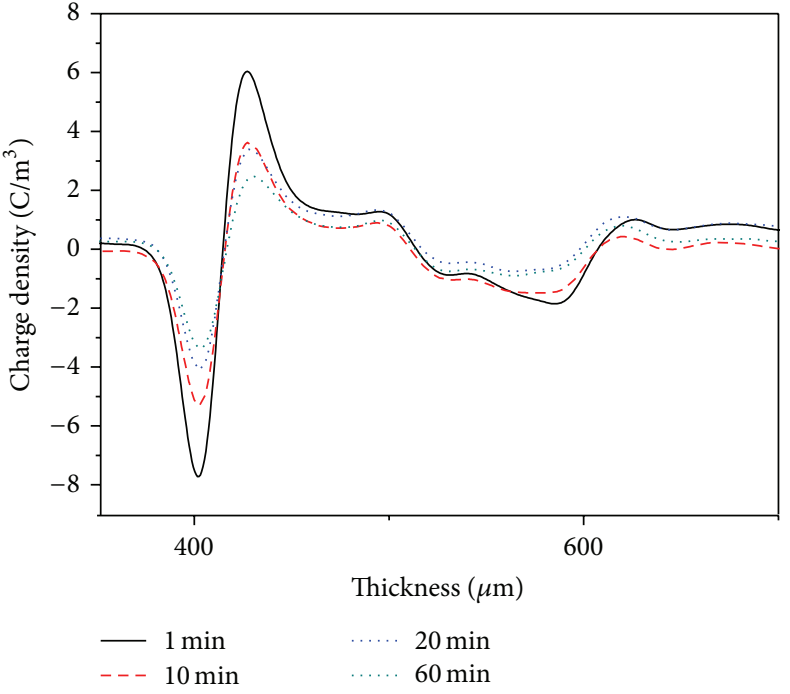

(b) $15 \mathrm{~nm}$; concentration is $5 \mathrm{wt} \%$

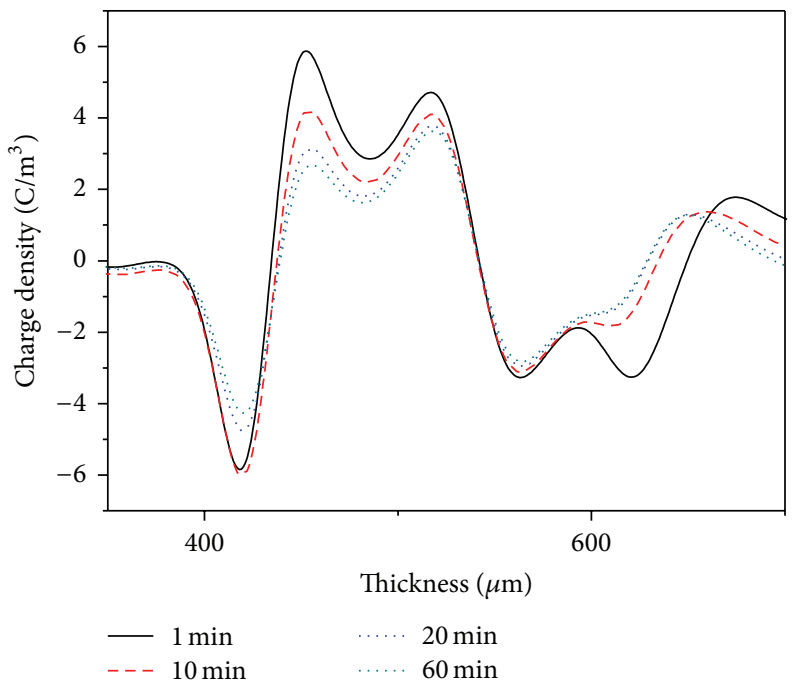

(c) $50 \mathrm{~nm}$; concentration is $5 \mathrm{wt} \%$

Figure 6: Detrapping characteristics of space charge with elongation of $10 \%$.

polymer matrix, the force between polymer molecules can be regarded to be larger than the force between polymer matrix and nanoparticles. Therefore, the elongation between polymer matrix and nanoparticles is larger than the elongation between polymer molecules.

Owing to the interface layer characteristics, many shallow traps exist in the polyethylene/silica nanocomposites, which are distributed in the interface layer. There is a large increase in the interface layer when the nanocomposites are in elongation because of the small force between nanoparticles and polymer. Therefore, the area of the interface layer between nanoparticles and polymer matrix exhibits an obvious increase, which may change the shallow traps into deep traps and generate packet-like space charges.

According to the induced dipole model and interface layer characteristics, space charge accumulation should exist in all nanocomposites theoretically because the nanoparticles are distributed in all nanocomposites. However, the test results in this study show that packet-like space charges exist in the interior of polyethylene/silica nanocomposites. This phenomenon can be explained by the repulsion of similar charges. The space charge near electrodes is forced to move to the interior of polyethylene/silica nanocomposites, which causes packet-like space charges.

\section{Conclusions}

This study investigated the space charge characteristics of polyethylene/silica nanocomposites whose elongation is 3\% and $6 \%$. The packet-like space charges in polyethylene/silica nanocomposites whose elongation is $10 \%$ were also examined. The main conclusions are as follows.

Suppressing the space charge in polyethylene/silica nanocomposites whose particle size is $15 \mathrm{~nm}$ and concentration is $3 \mathrm{wt} \%$ is effective. Homocharges near positive and negative electrodes are generated with the increase of particle size 
and concentration in the polyethylene/silica nanocomposites. The interface layer characteristics between nanoparticles and polymer matrix were used to explain these phenomena. The effect of nanoparticles on space charge in polyethylene/silica nanocomposites is mainly caused by interface layer characteristics between nanoparticles and polymer matrix. By using (2), the total surface area in unit volume is $0.872 \mathrm{~km}^{2} / \mathrm{m}^{3}$ in polyethylene/silica nanocomposites whose particle size is $50 \mathrm{~nm}$; the total surface area in unit volume is $2.8 \mathrm{~km}^{2} / \mathrm{m}^{3}$ in polyethylene/silica nanocomposites whose particle size is $15 \mathrm{~nm}$. The difference is large. Therefore, the interface layer characteristics are the main reason for the effect of space charge characteristics in nanocomposites. The total surface area in unit volume increases with the increase in particle size and concentration.

With the increase in elongation, an obvious increase in space charge accumulation occurred in the three nanocomposites. The homocharges accumulated near electrodes in the LDPE and were reduced with the increase in depth of samples. A dipole model was used to explain this phenomenon. The electrical potential distribution caused by the dipole model, which consisted of carbonyl $(\mathrm{C}=\mathrm{O})$ and hydroxyl $(\mathrm{OH})$ defects, can be regarded as the space charge traps in nanocomposites, to a certain extent. The bond length of the carbonyl $(\mathrm{C}=\mathrm{O})$ and hydroxyl $(\mathrm{OH})$ defects may be larger when polyethylene/silica nanocomposites were in elongation. According to (3), the elongation of carbonyl $(\mathrm{C}=\mathrm{O})$ and hydroxyl $(\mathrm{OH})$ defects caused the increase in electrical potential distribution, which in turn increased the amount of deep traps in polyethylene/silica nanocomposites and the amount of space charge.

Packet-like space charges were observed in polyethylene/silica nanocomposites whose particle size is 15 and $50 \mathrm{~nm}$ when elongation is $10 \%$. The packet-like space charges are more obvious in the nanocomposites whose particle size is $50 \mathrm{~nm}$. These phenomena can be explained from two aspects. First, induction charge exists on the surface of nanoparticles in the DC electric field; induced dipole and induction electromotive force are thus formed. The diameter of nanoparticles increases when nanocomposites are in elongation. According to (5), the amount of space charge and depth of charge traps increase with the increase in diameter of nanoparticles; this theory also explains why the amount of space charge increases with the increase in particle size. Second, the tensile force between nanoparticles and polymer matrix is weaker than that between polymer molecules because of the interface layer characteristics. Therefore, larger elongation exists between nanoparticles and polymer matrix, which may make the interface layer characteristics more obvious and could result in the generation of more charge traps. According to these theories, space charge is distributed in all nanocomposites. Packet-like space charges are created in polyethylene/silica nanocomposites because of the rejection of homocharges.

\section{Conflict of Interests}

The authors declare that there is no conflict of interests regarding the publication of this paper.

\section{Acknowledgment}

This research was supported by State Key Laboratory of Power Transmission Equipment \& System Security and New Technology of China (2007DA10512713205).

\section{References}

[1] Y. Zhang, J. Lewiner, C. Alquié, and N. Hampton, "Evidence of strong correlation between space-charge buildup and breakdown in cable insulation," IEEE Transactions on Dielectrics and Electrical Insulation, vol. 3, no. 6, pp. 778-783, 1996.

[2] S. Boggs, "A rational consideration of space charge," IEEE Electrical Insulation Magazine, vol. 20, no. 4, pp. 22-27, 2004.

[3] J. K. Nelson, "Overview of nanodielectrics: insulating materials of the future," in Proceedings of the Electrical Insulation Conference and Electrical Manufacturing Expo, pp. 229-235, October 2007.

[4] M. G. Danikas and T. Tanaka, "Nanocomposites-a review of electrical treeing and breakdown," IEEE Transactions on Electrical Insulation Magazine, vol. 25, no. 4, pp. 19-25, 2009.

[5] K. S. Shah, R. C. Jain, V. Shrinet, A. K. Singh, and D. P. Bharambe, "High density polyethylene (HDPE) clay nanocomposite for dielectric applications," IEEE Transactions on Dielectrics and Electrical Insulation, vol. 16, no. 3, pp. 853-861, 2009.

[6] Z. Li, Y. Yin, X. Dong, X. Li, and D. Xiao, "Effect of electrical stressing history on slow polarization behavior in composite of low-density polyethylene and nano- $\mathrm{SiO}_{x}$," Japanese Journal of Applied Physics, vol. 46, no. 9R, pp. 5908-5910, 2007.

[7] A. Bulinski, S. S. Bamji, J. M. Braun, and J. Densley, "Water treeing degradation under combined mechanical and electrical stresses," in Proceedings of the Conference on Electrical Insulation and Dielectric Phenomena, Annual Report, pp. 610-617, Victoria, Canada, October 1992.

[8] N. Amyot, E. David, S. Y. Lee, and I. H. Lee, "Influence of postmanufacturing residual mechanical stress and crosslinking byproducts on dielectric strength of HV extruded cables," IEEE Transactions on Dielectrics and Electrical Insulation, vol. 9, no. 3, pp. 458-466, 2002.

[9] F. Zheng, Z. Zhang, and C. Xiao, "Effect of applied mechanical stress on insulation of space charge breakdown," Transactions of China Electrotechnical Society, vol. 21, no. 2, pp. 31-34, 2006.

[10] E. Ildstad, T. A. Lindseth, and H. Faremo, "Water treeing of XLPE cables during dynamic mechanical tension," in Proceedings of the 19th IEEE International Symposium on Electrical Insulation (ISEI '12), pp. 628-631, San Juan, Puerto Rico, June 2012.

[11] J. C. Fothergill, "Filamentary electromechanical breakdown," IEEE Transactions on Electrical Insulation, vol. 26, no. 6, pp. 1124-1129, 1991.

[12] J. Wu, Y. Yin, L. Lan, Q. Wang, X. Li, and D. Xiao, "The influence of nano-filler concentration on space charge behavior in LDPE/silica nanocomposites," Proceedings of the Chinese Society of Electrical Engineering, vol. 32, no. 28, pp. 177-183, 2012.

[13] J. Wu, Y. Yin, L. Lan, and et al, "Space charge trapping and conduction in low-density polyethylene/silica nanocomposite," Japanese Journal of Applied Physics, vol. 51, no. 4, Article ID 041602, 2012.

[14] M. Meunier, N. Quirke, and A. Aslanides, "Molecular modeling of electron traps in polymer insulators: chemical defects and 
impurities," The Journal of Chemical Physics, vol. 115, no. 6, pp. 2876-2881, 2001.

[15] T. J. Lewis, "Interfaces are the dominant feature of dielectrics at the nanometric level," IEEE Transactions on Dielectrics and Electrical Insulation, vol. 11, no. 5, pp. 739-753, 2004.

[16] T. Tanaka, M. Kozako, N. Fuse, and Y. Ohki, "Proposal of a multi-core model for polymer nanocomposite dielectrics," IEEE Transactions on Dielectrics and Electrical Insulation, vol. 12, no. 4, pp. 669-681, 2005.

[17] T. Takada, Y. Hayase, Y. Tanaka, and T. Okamoto, "Space charge trapping in electrical potential well caused by permanent and induced dipoles for LDPE/MgO nanocomposite," IEEE Transactions on Dielectrics and Electrical Insulation, vol. 15, no. 1, pp. 152-160, 2008.

[18] M. Roy, J. K. Nelson, R. K. MacCrone, and L. S. Schadler, "Candidate mechanisms controlling the electrical characteristics of silica/XLPE nanodielectrics," Journal of Materials Science, vol. 42, no. 11, pp. 3789-3799, 2007. 

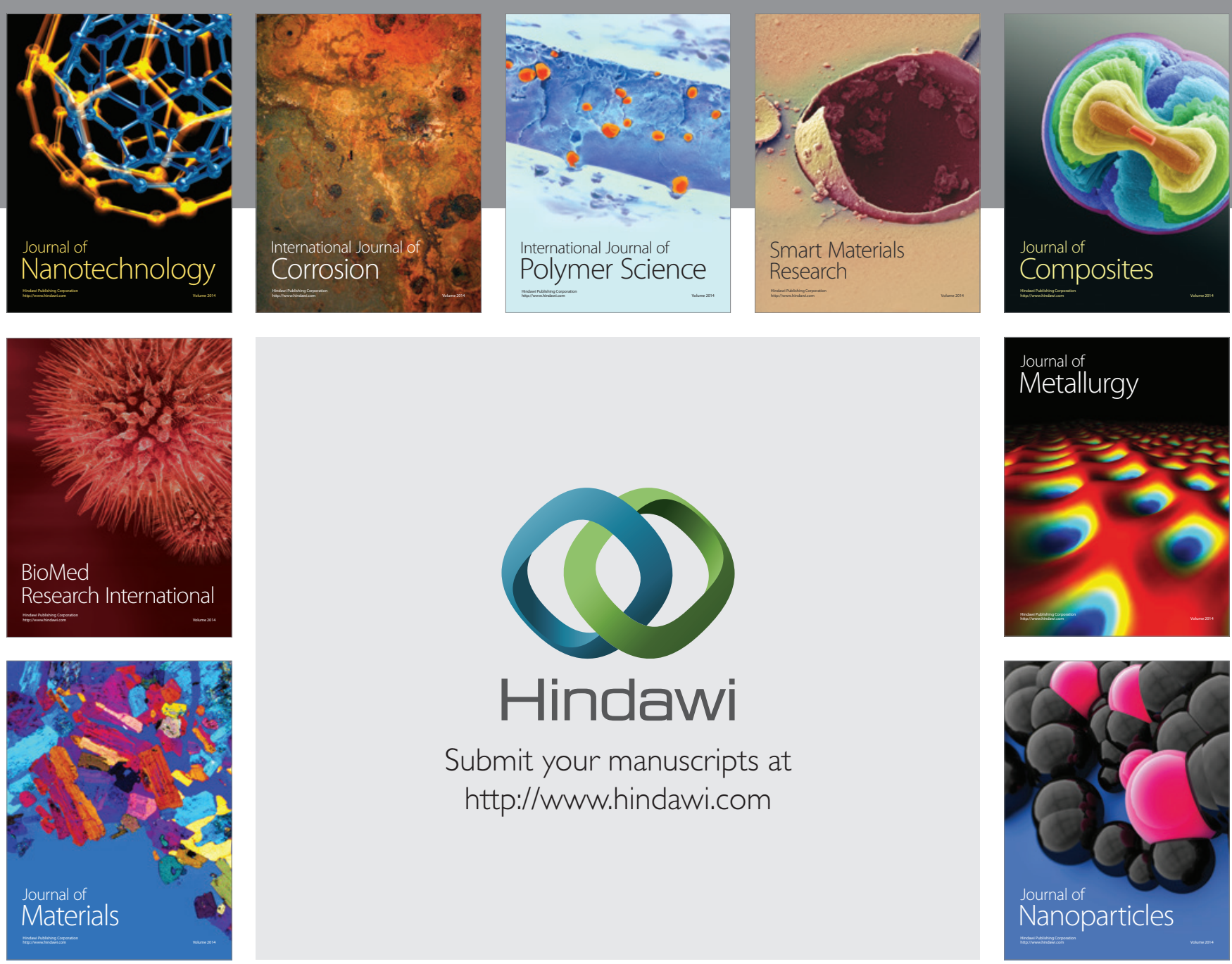

Submit your manuscripts at http://www.hindawi.com
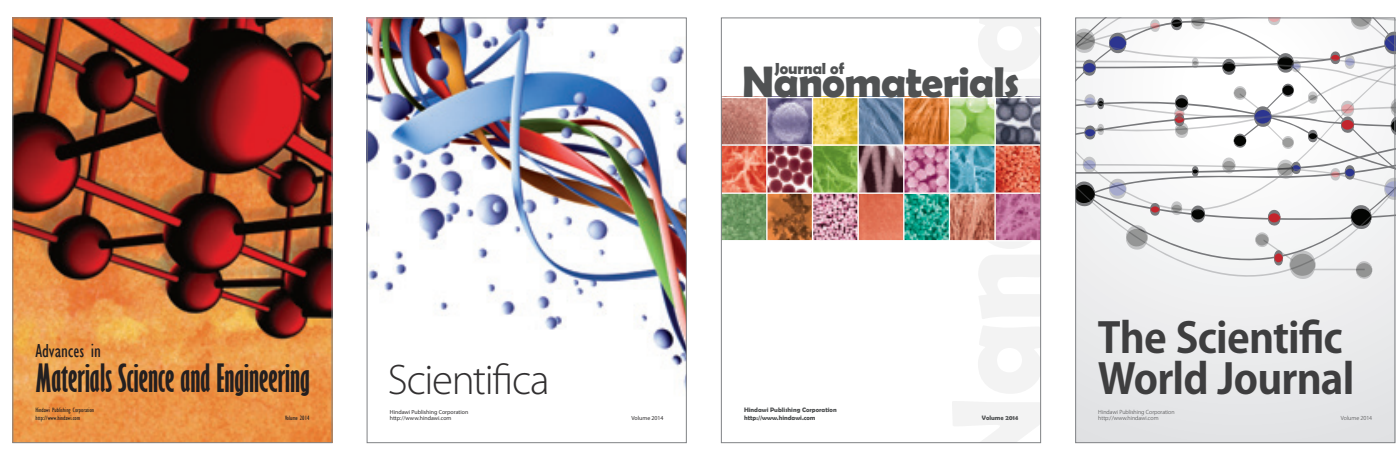

\section{The Scientific World Journal}
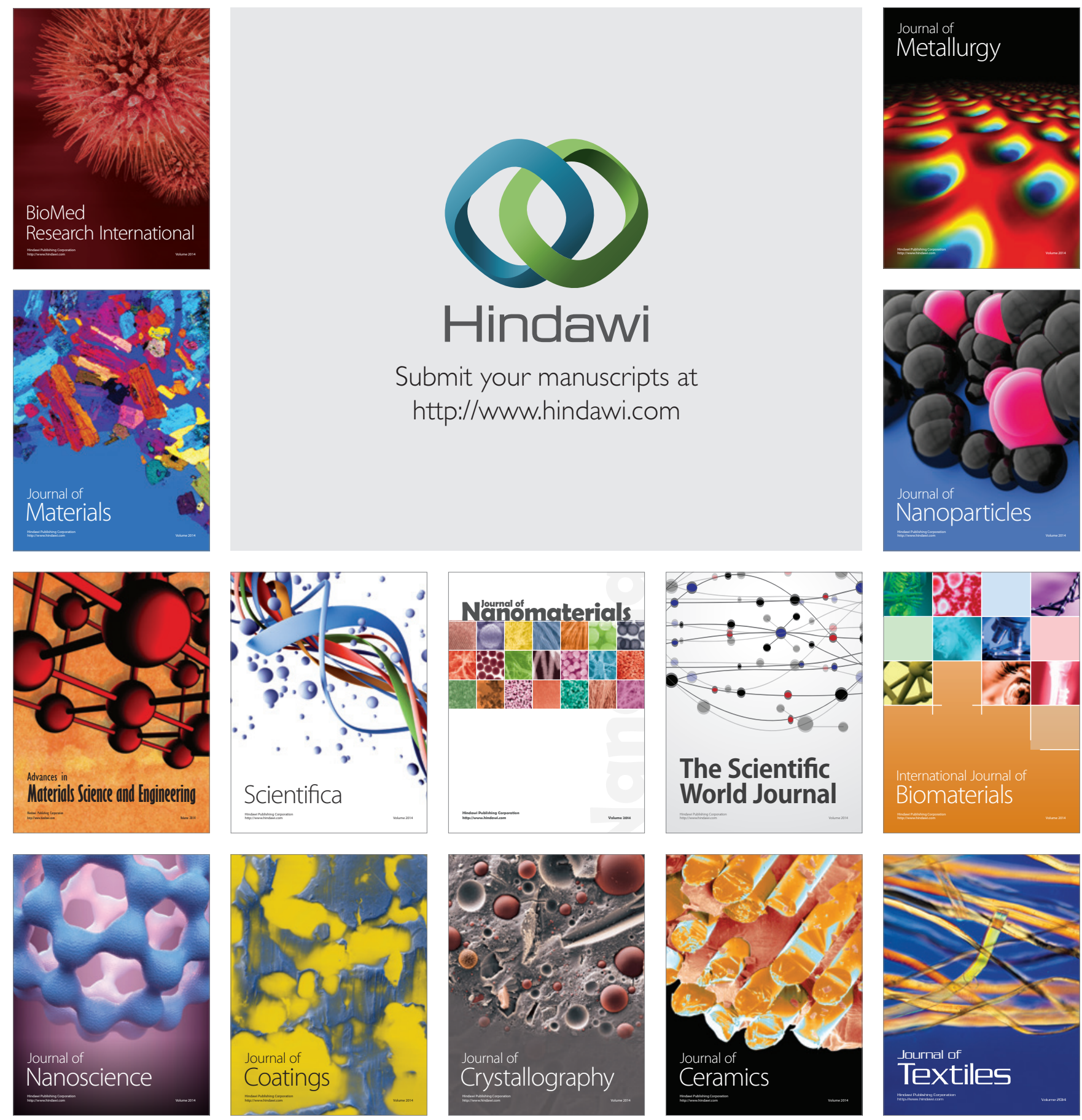